\title{
Mixed convective flow of immiscible viscous fluids confined between a long vertical wavy wall and a parallel flat wall
}

\author{
J.C. Umavathi", J. Prathap Kumar and M. Shekar \\ Department of Mathematics, Gulbarga University, Gulbarga, Karnataka-INDIA \\ *Corresponding Author: jc_uma11@yhaoo.com
}

\begin{abstract}
In this work, the flow and heat transfer in a long vertical channel composed of a smooth and a corrugated wall filled with two immiscible viscous fluids is studied under laminar flow conditions. Non-linear equations governing the motion have been solved by linearization technique, wherein the flow is assumed to be in two parts; a mean part and a perturbed part. Exact solutions are obtained for the mean part and a perturbed part using long wave approximation. Separate solutions are matched at the interface using suitable matching conditions. The results are presented graphically for various governing parameters such as Grashof number, viscosity ratio, width ratio and conductivity ratio. The effect of these parameters on the physical characteristics such as Nusselt number and skin friction at the walls is studied. It is found that Grashof number, viscosity ratio and width ratio enhance the flow whereas, conductivity ratio reduces the flow. Rate of heat transfer and skin friction for varying parameters is also shown graphically.
\end{abstract}

Keywords: wavy wall; perturbation method; immiscible fluids.

\section{Introduction}

Study of mixed convection in the channels has been to the focus of a lot of investigations during the last three decades because of the multiple applications in which it is involved. The fluid dynamics and thermal phenomena occurring in corrugated wall channels have been studied in different engineering sectors. Corrugated surfaces are, for example, utilized in compact heat exchangers (Kays and London, 1984). The study of heat transfer through corrugated surface is also particularly interesting in the cooling of electronic devices and systems (Bar and Kruas, 1990; Cesini et al., 1992). The corrugated wall channel is one of several devices employed for enhancing the heat transfer efficiency of industrial transport processes. The problem of viscous flow in a wavy channel was first treated analytically by Burns and Parks (1967), who expressed the stream function as a Fourier series under the assumption of Stokes flow. Following this, Goldstein and Sparrow (1977) were the first to use the naphthalene technique to measure local and average heat transfer coefficients in a corrugated wall channel (with 'triangular waves'). Their experiments in laminar, transitional turbulent flows used two corrugation cycles (i.e. two wavelengths). They observed secondary flows in the regions of high resolution local mass transfer measurement, and comparison of their results with those obtained with parallel-plate channels showed a three fold enhancement in the average heat transfer in the turbulent regimes.

Wang and Vanka (1995) determined the rates of heat transfer for a flow through a periodic array of wavy passage. They observed that for the steady-flow regime, the average Nusselt numbers for the wavy-wall channel were only slightly larger than those for a parallel-plate channel. However, in the transitional-flow regime, the enhancement of heat transfer was by a factor of approximately 2.5. Friction factors for the wavy channel were about twice those for the parallel-plate channel in the steady-flow region, and remained almost constant in the transitional regime. Although, some studies for steady and unsteady flows have been reported, example, Blancher et al. (1998), Selvarajan et al. (1998), Greiner et al. (1991) and Wirtz et al. (1999), little knowledge is available on the flow in these wavy channels.

Rees and Pop (1994) gave a short note on free convection along a vertical wavy surface in porous medium. Malashetty et al. (2001) studied the magnetoconvective flow and heat transfer between vertical wavy wall and a parallel flat wall. Wang and Chen 
(2001) studied the transient behavior of the laminar mixed convection in micropolar fluid flow over a vertical wavy surface. Wang and Chen (2002) also analyzed the rate of heat transfer for flow through a sinusoidal curved channel. A numerical study of mixed convection heat and mass transfer along a vertical wavy surface has been carried out by Jang and Yan (2004). Yao (2006) used finite difference methods to analyze the problem of natural convection boundary layer flow along a complex vertical surface represented by two sinusoidal functions. He found that the total heat-transfer rates for a complex surface are greater than those for a flat surface. Usha and Uma (2004) analyzed the long waves on a viscoelastic film flow down a wavy inclined plane.

The majority of the existing research has been principally devoted to the case of a single fluid filling the entire enclosure. Most of the problems arising in petroleum industry, geophysics, astrophysics, atmospheric physics and many other instances involve multi-fluid flow system. A number of complex, interacting transport phenomena may take place in a non-isothermal multi fluid system. Traditionally, macroscopic problems of a multi fluid flow and transport are modeled in which various fluids are regarded as distinct fluids with individual thermodynamics and transport phenomena and are mathematically described separately by basic principles of convection of each fluid and by appropriate interfacial conditions between viscous fluids. An important assumption usually encountered in this model is the interfacial viscous and thermal equilibrium between the fluids. Meyer and Garder (1954) were the first authors to publish a paper on mechanics of two immiscible fluids in porous media. Loharsabi and Sahai (1998) analyzed the flow of two immiscible fluids in a parallel plate channel assuming continuity of velocity and thermal equilibrium at the interface. Vafai and Kim (1995) suggested that porous medium/clear fluid interface is best dealt with Brinkman-Forchhiemerextended Darcy formulation and the assumption of continuity of velocities and stress at the interface. Using this assumption, Malashetty et al. (1997, 2001, 2006) and Umavathi et al. (2005, 2006, 2007, 2008), Prathap Kumar et. al. (2010a, 2010b) studied flow and heat transfer of different immiscible fluids through channels.

Keeping in view the practical applications on mixed convection flow in wavy channels, an attempt is made in this study to investigate the fully developed mixed convection flow of two immiscible fluids in a vertical wavy channel.

\section{Mathematical formulation of the problem}

We consider a two dimensional steady laminar mixed convective flow of two incompressible fluids in a vertical channel with one wavy wall and another flat wall as shown in Figure1. The $X$-axis is taken parallel to the flat wall, while the $Y$-axis is taken perpendicular to it in such a way that the wavy wall is represented by $Y=-h^{(1)}+a \cos \left(\lambda^{*} X\right)$ and the flat wall by $Y=h^{(2)}$. The wavy and flat walls are maintained at constant temperatures $T_{w}$ and $T_{1}$ respectively. The region $-h^{(1)} \leq Y \leq 0$ (Region-I) is occupied by a fluid of density $\rho^{(1)}$, viscosity $\mu^{(1)}$, thermal conductivity $K^{(1)}$, thermal expansion coefficient $\beta^{(1)}$, specific heat at constant pressure $C_{p}^{(1)}$, and the region $0 \leq Y \leq h^{(2)}$ (region-II) is occupied by the fluid of density $\rho^{(2)}$, viscosity $\mu^{(2)}$, thermal conductivity $K^{(2)}$, thermal expansion coefficient $\beta^{(2)}$, specific heat at constant pressure $C_{p}^{(2)}$. The fluid properties are assumed to

be constant except the density in the buoyancy term in the momentum equation. The fluid rises in the channel driven by buoyancy forces. The transport properties of both the fluids are assumed to be constant. The wave length of the wavy wall which is proportional to $a^{-1}$ is very large where $a$ is the amplitude.

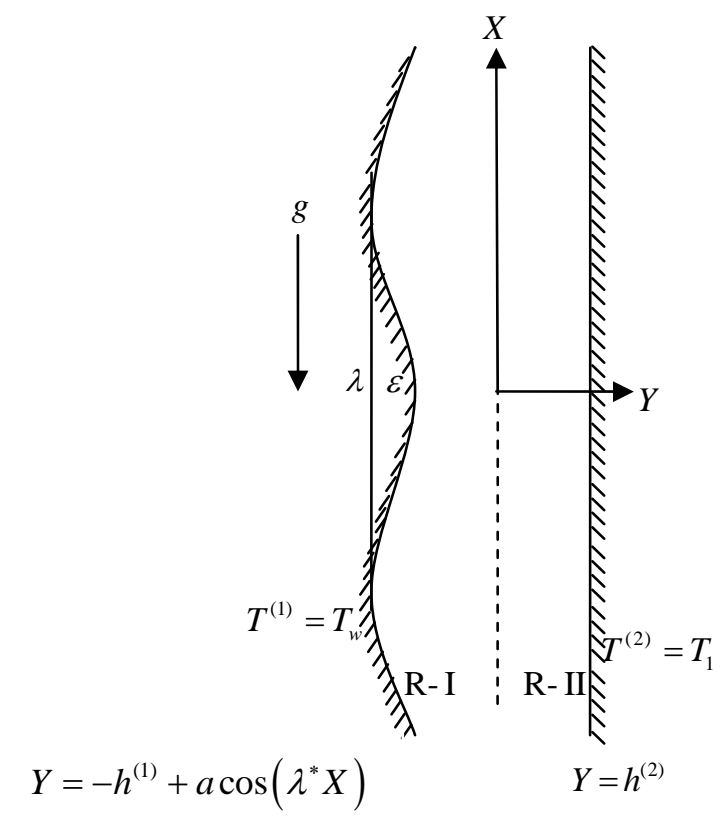

Figure 1: Physical model and the coordinate system. 
We make the Boussinesq approximation that the density is constant everywhere except when it is multiplied by gravity. Under these assumptions, the continuity, momentum, energy and state equations yield.

Region - I

$$
\begin{gathered}
\frac{\partial U^{(1)}}{\partial X^{(1)}}+\frac{\partial V^{(1)}}{\partial Y^{(1)}}=0 \\
\rho^{(1)}\left(U^{(1)} \frac{\partial U^{(1)}}{\partial X^{(1)}}+V^{(1)} \frac{\partial U^{(1)}}{\partial Y^{(1)}}\right)=-\frac{\partial P^{(1)}}{\partial X^{(1)}}+\mu^{(1)} \nabla^{2} U^{(1)}-\rho^{(1)} g \\
\rho^{(1)}\left(U^{(1)} \frac{\partial V^{(1)}}{\partial X^{(1)}}+V^{(1)} \frac{\partial V^{(1)}}{\partial Y^{(1)}}\right)=-\frac{\partial P^{(1)}}{\partial Y^{(1)}}+\mu^{(1)} \nabla^{2} V^{(1)} \\
\rho^{(1)} C_{p}^{(1)}\left(U^{(1)} \frac{\partial T^{(1)}}{\partial X^{(1)}}+V^{(1)} \frac{\partial T^{(1)}}{\partial Y^{(1)}}\right)=K^{(1)} \nabla^{2} T^{(1)} \\
\rho^{(1)}=\rho_{0}\left(1-\beta^{(1)}\left(T^{(1)}-T_{s}\right)\right)
\end{gathered}
$$

Region - II

$$
\begin{gathered}
\frac{\partial U^{(2)}}{\partial X^{(2)}}+\frac{\partial V^{(2)}}{\partial Y^{(2)}}=0 \\
\rho^{(2)}\left(U^{(2)} \frac{\partial U^{(2)}}{\partial X^{(2)}}+V^{(2)} \frac{\partial U^{(2)}}{\partial Y^{(2)}}\right)=-\frac{\partial P^{(2)}}{\partial X^{(2)}}+\mu^{(2)} \nabla^{2} U^{(2)}-\rho^{(2)} g \\
\rho^{(2)}\left(U^{(2)} \frac{\partial V^{(2)}}{\partial X^{(2)}}+V^{(2)} \frac{\partial V^{(2)}}{\partial Y^{(2)}}\right)=-\frac{\partial P^{(2)}}{\partial Y^{(2)}}+\mu^{(2)} \nabla^{2} V^{(2)} \\
\rho^{(2)} C_{p}^{(2)}\left(U^{(2)} \frac{\partial T^{(2)}}{\partial X^{(2)}}+V^{(2)} \frac{\partial T^{(2)}}{\partial Y^{(2)}}\right)=K^{(2)} \nabla^{2} T^{(2)} \\
\rho^{(2)}=\rho_{0}\left(1-\beta^{(2)}\left(T^{(2)}-T_{s}\right)\right)
\end{gathered}
$$

The boundary conditions on $U^{(i)}, V^{(i)}$ are both no-slip conditions and boundary conditions on $T$ are $T_{w}$ at the left wall and $T_{1}$ at the right wall. For the problem displayed in Figure 1 at fluids interface, we utilize the assumption of continuity of velocity, continuity of shear stress, continuity of pressure gradient along the flow direction, continuity of temperature and continuity of heat flux which are given below.

The relevant boundary and interface conditions on velocity are

$$
\begin{gathered}
U^{(1)}=V^{(1)}=0 \quad \text { at } \quad Y=-h^{(1)}+a \cos \left(\lambda^{*} X\right) \\
U^{(2)}=V^{(2)}=0 \text { at } \quad Y=h^{(2)} \\
U^{(1)}=U^{(2)} ; \quad V^{(1)}=V^{(2)} ; \quad \mu^{(1)}\left(\frac{\partial U}{\partial Y}+\frac{\partial V}{\partial X}\right)^{(1)}=\mu^{(2)}\left(\frac{\partial U}{\partial Y}+\frac{\partial V}{\partial X}\right)^{(2)} \text { at } \quad Y=0 \\
\frac{\partial P^{(1)}}{\partial X^{(1)}}=\frac{\partial P^{(2)}}{\partial X^{(2)}} \text { at } \quad Y=0
\end{gathered}
$$

The relevant boundary and interface conditions on temperature are

$$
\begin{array}{r}
T^{(1)}=T_{w} \text { at } \quad Y=-h^{(1)}+a \cos \left(\lambda^{*} X\right) \\
T^{(2)}=T_{1} \text { at } Y=h^{(2)} \\
T^{(1)}=T^{(2)} ; \quad K^{(1)}\left(\frac{\partial T}{\partial Y}+\frac{\partial T}{\partial X}\right)^{(1)}=K^{(2)}\left(\frac{\partial T}{\partial Y}+\frac{\partial T}{\partial X}\right)^{(2)} \text { at } Y=0
\end{array}
$$

We next introduce the non-dimensional flow variables as

$$
\begin{gathered}
x^{(1)}=\frac{X^{(1)}}{h^{(1)}}, y^{(1)}=\frac{Y^{(1)}}{h^{(1)}}, x^{(2)}=\frac{X^{(2)}}{h^{(2)}}, y^{(2)}=\frac{Y^{(2)}}{h^{(2)}}, u^{(1)}=\frac{h^{(1)}}{v^{(1)}} U^{(1)}, v^{(1)}=\frac{h^{(1)}}{v^{(1)}} V^{(1)}, u^{(2)}=\frac{h^{(2)}}{v^{(2)}} U^{(2)}, v^{(2)}=\frac{h^{(2)}}{v^{(2)}} V^{(2)}, \\
p^{(1)}=\frac{P^{(1)}}{\rho^{(1)}\left(v^{(1)} / h^{(1)}\right)^{2}}, p^{(2)}=\frac{P^{(2)}}{\rho^{(2)}\left(v^{(2)} / h^{(2)}\right)^{2}}, \theta^{(1)}=\frac{T^{(1)}-T_{s}}{T_{w}-T_{s}}, \\
\theta^{(2)}=\frac{T^{(2)}-T_{s}}{T_{w}-T_{s}}, \beta=\frac{\beta^{(2)}}{\beta^{(1)}}, h=\frac{h^{(2)}}{h^{(1)}}, m=\frac{\mu^{(1)}}{\mu^{(2)}}, r=\frac{\rho^{(2)}}{\rho^{(1)}}, k=\frac{K^{(2)}}{K^{(1)}}, C_{p}=\frac{C_{p}^{(1)}}{C_{p}^{(2)}},
\end{gathered}
$$




$$
G r=\frac{h^{(1)^{3}} g \beta^{(1)} \Delta T}{v^{(1)^{2}}}, \Delta T=T_{w}-T_{s}, \bar{\theta}=\frac{T_{1}-T_{s}}{T_{w}-T_{s}}, \operatorname{Pr}=\frac{C_{p}^{(1)} \mu^{(1)}}{K^{(1)}}
$$

In terms of these non-dimensional variables, the basic equations (1) to (8) can be expressed in the dimensionless form, as, (for simplicity, the notation is considered as $x^{(1)}=x ; y^{(1)}=y$ in region-I and $x^{(2)}=x ; y^{(2)}=y$ in region-II)

Region - I

$$
\begin{gathered}
\frac{\partial u^{(1)}}{\partial x}+\frac{\partial v^{(1)}}{\partial y}=0 \\
u^{(1)} \frac{\partial u^{(1)}}{\partial x}+v^{(1)} \frac{\partial u^{(1)}}{\partial y}=-\frac{\partial p^{(1)}}{\partial x}+\frac{\partial^{2} u^{(1)}}{\partial x^{2}}+\frac{\partial^{2} u^{(1)}}{\partial y^{2}}+G r \theta^{(1)} \\
u^{(1)} \frac{\partial v^{(1)}}{\partial x}+v^{(1)} \frac{\partial v^{(1)}}{\partial y}=-\frac{\partial p^{(1)}}{\partial y}+\frac{\partial^{2} v^{(1)}}{\partial x^{2}}+\frac{\partial^{2} v^{(1)}}{\partial y^{2}} \\
u^{(1)} \frac{\partial \theta^{(1)}}{\partial x}+v^{(1)} \frac{\partial \theta^{(1)}}{\partial y}=\frac{1}{\operatorname{Pr}}\left(\frac{\partial^{2} \theta^{(1)}}{\partial x^{2}}+\frac{\partial^{2} \theta^{(1)}}{\partial y^{2}}\right)
\end{gathered}
$$

Region - II

$$
\begin{gathered}
\frac{\partial u^{(2)}}{\partial x}+\frac{\partial v^{(2)}}{\partial y}=0 \\
u^{(2)} \frac{\partial u^{(2)}}{\partial x}+v^{(2)} \frac{\partial u^{(2)}}{\partial y}=-\frac{\partial p^{(2)}}{\partial x}+\frac{\partial^{2} u^{(2)}}{\partial x^{2}}+\frac{\partial^{2} u^{(2)}}{\partial y^{2}}+G r \beta h^{3} m^{2} r^{2} \theta^{(2)} \\
u^{(2)} \frac{\partial v^{(2)}}{\partial x}+v^{(2)} \frac{\partial v^{(2)}}{\partial y}=-\frac{\partial p^{(2)}}{\partial y}+\frac{\partial^{2} v^{(2)}}{\partial x^{2}}+\frac{\partial^{2} v^{(2)}}{\partial y^{2}} \\
u^{(2)} \frac{\partial \theta^{(2)}}{\partial x}+v^{(2)} \frac{\partial \theta^{(2)}}{\partial y}=\frac{k m C_{p}}{\operatorname{Pr}}\left(\frac{\partial^{2} \theta^{(2)}}{\partial x^{2}}+\frac{\partial^{2} \theta^{(2)}}{\partial y^{2}}\right)
\end{gathered}
$$

Using Eqn. (11) boundary and interface conditions Eqn. (9) for velocity field become

$$
\begin{gathered}
u^{(1)}=v^{(1)}=0 \text { at } \quad y=-1+\varepsilon \cos (\lambda x) \\
u^{(2)}=v^{(2)}=0 \text { at } y=1 \\
u^{(1)}=\frac{u^{(2)}}{m h r} ; \quad v^{(1)}=\frac{v^{(2)}}{m h r} ; \quad\left(\frac{\partial u}{\partial y}+\frac{\partial v}{\partial x}\right)^{(1)}=\frac{1}{m^{2} h^{2} r}\left(\frac{\partial u}{\partial y}+\frac{\partial v}{\partial x}\right)^{(2)} \text { at } \quad y=0 \\
\frac{\partial p^{(1)}}{\partial x}=\frac{1}{r m^{2} h^{3}} \frac{\partial p^{(2)}}{\partial x} \text { at } \quad y=0
\end{gathered}
$$

Using Eqn. (11) boundary and interface conditions Eqn. (10) for temperature field become

$$
\begin{aligned}
& \theta^{(1)}=1 \text { at } \quad y=-1+\varepsilon \cos (\lambda x) \\
& \theta^{(2)}=\bar{\theta} \text { at } y=1 \\
& \theta^{(1)}=\theta^{(2)},\left(\frac{\partial \theta}{\partial y}+\frac{\partial \theta}{\partial x}\right)^{(1)}=\frac{k}{h}\left(\frac{\partial \theta}{\partial y}+\frac{\partial \theta}{\partial x}\right)^{(2)} \text { at } \quad y=0
\end{aligned}
$$

In the static fluid we have (see Vajravelu and Sastri 1978)

$$
0=-\frac{\partial p_{s}}{\partial x}-\frac{\rho_{0} g h^{(1)^{3}}}{\rho v^{(1)^{2}}}=-\frac{\partial p_{s}}{\partial x}-\frac{\rho_{0} g h^{(2)^{3}}}{\rho v^{(2)^{2}}}
$$

In view of Eqn. (22). Eqs. (13) and (17) becomes

$$
\begin{gathered}
u \frac{\partial u^{(1)}}{\partial x}+v \frac{\partial u^{(1)}}{\partial y}=-\frac{\partial\left(p^{(1)}-p_{s}\right)}{\partial x}+\frac{\partial^{2} u^{(1)}}{\partial x^{2}}+\frac{\partial^{2} u^{(1)}}{\partial y^{2}}+\operatorname{Gr} \theta^{(1)} \\
u^{(2)} \frac{\partial u^{(2)}}{\partial x}+v^{(2)} \frac{\partial u^{(2)}}{\partial y}=-\frac{\partial\left(p^{(2)}-p_{s}\right)}{\partial x}+\frac{\partial^{2} u^{(2)}}{\partial x^{2}}+\frac{\partial^{2} u^{(2)}}{\partial y^{2}}+G r \beta h^{3} m^{2} r^{2} \theta^{(2)}
\end{gathered}
$$




\section{Solutions to the problem}

Equations (12), (14)-(16), (18), (19), (23), and (24) are coupled nonlinear and are to be solved simultaneously. Due to the nonlinearity, analytical solutions are difficult; however approximate solutions can be obtained using perturbation techniques. Assuming that the solutions consists of a mean part and a perturbed part, velocity, pressure and temperature can be written as,

$$
\begin{gathered}
u(x, y)=u_{0}(y)+u_{1}(x, y) \\
v(x, y)=v_{1}(x, y) \\
p(x, y)=p_{0}(x, y)+p_{1}(x, y) \\
\theta(x, y)=\theta_{0}(y)+\theta_{1}(x, y)
\end{gathered}
$$

where the perturbed quantities $u_{1}, v_{1}, p_{1}$ and $\theta_{1}$ are small compared with the mean or zeroth order quantities.

Using Eqs. (25) to (28) in the Eqs. (12), (14)-(16), (18), (19), (23), and (24) and separating mean and perturbed parts, gives the following equations.

Zeroth order equations

Region -I

$$
\begin{gathered}
\frac{d^{2} \theta_{0}^{(1)}}{d y^{2}}=0 \\
\frac{d^{2} u_{0}^{(1)}}{d y^{2}}+G r \theta_{0}^{(1)}=C
\end{gathered}
$$

Region -II

$$
\begin{gathered}
\frac{d^{2} \theta_{0}^{(2)}}{d y^{2}}=0 \\
\frac{d^{2} u_{0}^{(2)}}{d y^{2}}+G r \beta h^{3} m^{2} r^{2} \theta_{0}^{(2)}=C
\end{gathered}
$$

where $C=\frac{\partial}{\partial x}\left(p_{0}^{(j)}-p_{s}\right)$, and is taken to be zero (see Ostrach 1952) for $j=1,2$

First order equations

Region -I

$$
\begin{gathered}
\frac{\partial u_{1}^{(1)}}{\partial x}+\frac{\partial v_{1}^{(1)}}{\partial y}=0 \\
u_{0}^{(1)} \frac{\partial u_{1}^{(1)}}{\partial x}+v_{1}^{(1)} \frac{d u_{0}^{(1)}}{d y}=-\frac{\partial p_{1}^{(1)}}{\partial x}+\frac{\partial^{2} u_{1}^{(1)}}{\partial x^{2}}+\frac{\partial^{2} u_{1}^{(1)}}{\partial y^{2}}+G r \theta_{1}^{(1)} \\
u_{0}^{(1)} \frac{\partial v_{1}^{(1)}}{\partial x}=-\frac{\partial p_{1}^{(1)}}{\partial y}+\frac{\partial^{2} v_{1}^{(1)}}{\partial x^{2}}+\frac{\partial^{2} v_{1}^{(1)}}{\partial y^{2}} \\
u_{0}^{(1)} \frac{\partial \theta_{1}^{(1)}}{\partial x}+v_{1}^{(1)} \frac{d \theta_{0}^{(1)}}{d y}=\frac{1}{\operatorname{Pr}}\left(\frac{\partial^{2} \theta_{1}^{(1)}}{\partial x^{2}}+\frac{\partial^{2} \theta_{1}^{(1)}}{\partial y^{2}}\right)
\end{gathered}
$$

Region -II

$$
\begin{gathered}
\frac{\partial u_{1}^{(2)}}{\partial x}+\frac{\partial v_{1}^{(2)}}{\partial y}=0 \\
u_{0}^{(2)} \frac{\partial u_{1}^{(2)}}{\partial x}+v_{1}^{(2)} \frac{d u_{0}^{(2)}}{d y}=-\frac{\partial p_{1}^{(2)}}{\partial x}+\frac{\partial^{2} u_{1}^{(2)}}{\partial x^{2}}+\frac{\partial^{2} u_{1}^{(2)}}{\partial y^{2}}+G r \beta h^{3} m^{2} r^{2} \theta_{1}^{(2)} \\
u_{0}^{(2)} \frac{\partial v_{1}^{(2)}}{\partial x}=-\frac{\partial p_{1}^{(2)}}{\partial y}+\frac{\partial^{2} v_{1}^{(2)}}{\partial x^{2}}+\frac{\partial^{2} v_{1}^{(2)}}{\partial y^{2}} \\
u_{0}^{(2)} \frac{\partial \theta_{1}^{(2)}}{\partial x}+v_{1}^{(1)} \frac{d \theta_{0}^{(2)}}{d y}=\frac{k m C_{p}}{\operatorname{Pr}}\left(\frac{\partial^{2} \theta_{1}^{(2)}}{\partial x^{2}}+\frac{\partial^{2} \theta_{1}^{(2)}}{\partial y^{2}}\right)
\end{gathered}
$$

In view of Eqs. (25) to (28) the boundary and interface conditions Eqs. (20) and (21) can be split as follows, Zeroth order boundary and interface conditions for velocity and temperature are

$$
u_{0}^{(1)}=0 \text {, at } y=-1, \quad u_{0}^{(2)}=0 \text {, at } \quad y=1
$$




$$
\begin{aligned}
& u_{0}^{(1)}=\frac{1}{m h r} u_{0}^{(2)}, \frac{d u_{0}^{(1)}}{d y}=\frac{1}{m^{2} h^{2} r} \frac{d u_{0}^{(2)}}{d y} \quad \text { at } \quad y=0 \\
& \theta_{0}^{(1)}=1 \quad \text { at } \quad y=-1, \quad \theta_{0}^{(2)}=\bar{\theta} \quad \text { at } \quad y=1 \\
& \theta_{0}^{(1)}=\theta_{0}^{(2)}, \frac{d \theta_{0}^{(1)}}{d y}=\frac{k}{h} \frac{d \theta_{0}^{(2)}}{d y} \text { at } \quad y=0
\end{aligned}
$$

First order boundary and interface conditions for velocity and temperature are

$$
\begin{aligned}
& u_{1}^{(1)}=-\cos (\lambda x) \frac{d u_{0}^{(1)}}{d y}, \quad v_{1}^{(1)}=0 \quad \text { at } \quad y=-1 \\
& u_{1}^{(2)}=0, \quad v_{1}^{(2)}=0 \quad \text { at } \quad y=1 \\
& u_{1}^{(1)}=\frac{1}{m h r} u_{1}^{(2)}, \quad v_{1}^{(1)}=\frac{1}{m h r} v_{1}^{(2)} \quad \text { at } \quad y=0 \\
& \frac{d u_{1}^{(1)}}{d y}+\frac{d v_{1}^{(1)}}{d x}=\frac{1}{m^{2} h^{2} r}\left(\frac{d u_{1}^{(2)}}{d y}+\frac{d v_{1}^{(2)}}{d x}\right) \quad \text { at } \quad y=0 \\
& \frac{\partial p_{1}^{(1)}}{\partial x}=\frac{1}{r m^{2} h^{3}} \frac{\partial p_{1}^{(2)}}{\partial x} \quad \text { at } \quad y=0 \\
& \theta_{1}^{(1)}=-\cos (\lambda x) \frac{d \theta_{0}^{(1)}}{d y} \text { at } \quad y=-1, \theta_{1}^{(2)}=0 \quad \text { at } \quad y=1 \\
& \theta_{1}^{(1)}=\theta_{1}^{(2)}, \quad \frac{d \theta_{1}^{(1)}}{d y}+\frac{d \theta_{1}^{(1)}}{d x}=\frac{k}{h}\left(\frac{d \theta_{1}^{(2)}}{d y}+\frac{d \theta_{1}^{(2)}}{d x}\right) \text { at } \quad y=0
\end{aligned}
$$

In order to solve Eqs. (33) to (40), for the first order quantities it is convenient to introduce stream function $\bar{\psi}$ in the following form

$$
u_{1}^{(j)}=-\frac{\partial \bar{\psi}^{(j)}}{\partial y} \text { and } v_{1}^{(j)}=\frac{\partial \bar{\psi}^{(j)}}{\partial x} \quad \text { for } j=1,2
$$

The stream function approach reduces the number of dependent variables to be solved and also eliminates pressure from the list of variables. Differentiate Eqn. (34) with respect to $y$ and differentiate Eqn. (35) with respect to $x$ and then subtract Eqn. (34) with Eqn. (35) which will result in the elimination of pressure $p_{1}^{(1)}$. Similar procedure is opted for elimination of pressure $p_{1}^{(2)}$ from Eqs. (38) and (39). $\quad$ Equations.(33) to (40) after elimination of $p_{1}^{(1)}$ and $p_{1}^{(2)}$, can be expressed in terms of the stream function $\bar{\psi}$ in the form

Region-I

Region-II

$$
\begin{gathered}
u_{0}^{(1)} \bar{\psi}_{x y y}^{(1)}-\bar{\psi}_{x}^{(1)} u_{0 y y}^{(1)}+u_{0}^{(1)} \bar{\psi}_{x x x}^{(1)}-\bar{\psi}_{x x x x}^{(1)}-\bar{\psi}_{y y y y}^{(1)}-2 \bar{\psi}_{x x y y}^{(1)}+G r \theta_{1 y}^{(1)}=0 \\
u_{0}^{(1)} \theta_{1 x}^{(1)}+\bar{\psi}_{x}^{(1)} \theta_{0 y}^{(1)}=\frac{1}{\operatorname{Pr}}\left(\theta_{1 x x}^{(1)}+\theta_{1 y y}^{(1)}\right)
\end{gathered}
$$

$$
\begin{gathered}
u_{0}^{(2)} \bar{\psi}_{x y y}^{(2)}-\bar{\psi}_{x}^{(2)} u_{0 y y}^{(2)}+u_{0}^{(2)} \bar{\psi}_{x x x}^{(2)}-\bar{\psi}_{y y y y}^{(2)}-\bar{\psi}_{x x x x}^{(2)}-2 \bar{\psi}_{x x y y}^{(2)}+G r \beta h^{3} m^{2} r^{2} \theta_{1 y}^{(2)}=0 \\
u_{0}^{(2)} \theta_{1 x}^{(2)}+\bar{\psi}_{x}^{(2)} \theta_{0 y}^{(2)}=\frac{k m C_{p}}{\operatorname{Pr}}\left(\theta_{1 x x}^{(2)}+\theta_{1 y y}^{(2)}\right)
\end{gathered}
$$

where a suffix $x$ or $y$ represents derivative with respect to $x$ or $y$.

The corresponding boundary and interface conditions on velocity and temperature reduces to

$$
\begin{aligned}
& \bar{\psi}_{y}^{(1)}=\cos (\lambda x) u_{0 y}^{(1)}, \quad \bar{\psi}_{x}^{(1)}=0 \text { at } \quad y=-1 \\
& \bar{\psi}_{y}^{(2)}=0, \quad \bar{\psi}_{x}^{(2)}=0 \quad \text { at } \quad y=1 \\
& \bar{\psi}_{y}^{(1)}=\frac{\bar{\psi}_{y}^{(2)}}{m h r}, \quad \bar{\psi}_{x}^{(1)}=\frac{\bar{\psi}_{x}^{(2)}}{m h r}, \quad \bar{\psi}_{x x}^{(1)}-\bar{\psi}_{y y}^{(1)}=\frac{\bar{\psi}_{x x}^{(2)}-\bar{\psi}_{y y}^{(2)}}{m^{2} h^{2} r} \quad \text { at } y=0 \\
& -u_{0}^{(1)} \bar{\psi}_{x y}^{(1)}+\bar{\psi}_{x}^{(1)} u_{0 y}^{(1)}+\bar{\psi}_{x x y}^{(1)}+\bar{\psi}_{y y y}^{(1)}-G r \theta_{1}^{(1)}=\frac{1}{r m^{2} h^{3}}\left(-u_{0}^{(2)} \bar{\psi}_{x y}^{(2)}+\bar{\psi}_{x}^{(2)} u_{0 y}^{(2)}+\bar{\psi}_{x x y}^{(2)}+\bar{\psi}_{y y y}^{(2)}-G r \beta h^{3} m^{2} r^{2} \theta_{1}^{(2)}\right) \\
& \text { at } \quad y=0
\end{aligned}
$$




$$
\begin{array}{ccc}
\theta_{1}^{(1)}=-\cos (\lambda x) \theta_{0 y}^{(1)} \quad \text { at } y=-1, & \theta_{1}^{(2)}=0 \text { at } y=1 \\
\theta_{1}^{(1)}=\theta_{1}^{(2)}, \quad \theta_{1 x x}^{(1)}+\theta_{1 y y}^{(1)}=\frac{k\left(\theta_{1 x x}^{(2)}+\theta_{1 y y}^{(2)}\right)}{h} \text { at } & y=0
\end{array}
$$

We assume stream function and temperature in the following form

$$
\bar{\psi}^{(j)}=\varepsilon e^{i \lambda x} \psi(y)^{(j)}, \theta_{1}^{(j)}=\varepsilon e^{i \lambda x} t(y)^{(j)} \quad \text { for } j=1,2
$$

from which we infer

where $i$ is the imaginary unit.

$$
u_{1}(x, y)=\varepsilon e^{i \lambda x} u_{1}(y), v_{1}(x, y)=\varepsilon e^{i \lambda x} v_{1}(y)
$$

Region-I

In view of Eqn. (52), Eqs. (46) to (49) becomes

Region-II

$$
\begin{gathered}
\psi_{y y y y}^{(1)}-i\left(\lambda u_{0}^{(1)}+2 \lambda^{2}\right) \psi_{y y}^{(1)}+\left(i \lambda u_{0 y y}^{(1)}+i \lambda^{3}+\lambda^{4}\right) \psi^{(1)}-G r t_{y}^{(1)}=0 \\
i\left(\lambda u_{0}^{(1)} t^{(1)}+\lambda \theta_{0 y}^{(1)} \psi^{(1)}\right)=\frac{1}{\operatorname{Pr}}\left(-\lambda^{2} t^{(1)}+t_{y y}^{(1)}\right)
\end{gathered}
$$

$$
\begin{gathered}
\psi_{y y y y}^{(2)}-i\left(\lambda u_{0}^{(2)}+2 \lambda^{2}\right) \psi_{y y}^{(2)}+\left(i \lambda u_{0 y y}^{(2)}+i \lambda^{3}+\lambda^{4}\right) \psi^{(2)}-G r \beta h^{3} m^{2} r^{2} t_{y}^{(2)}=0 \\
i\left(\lambda u_{0}^{(2)} t^{(2)}+\lambda \theta_{0 y}^{(2)} \psi^{(2)}\right)=\frac{k m C_{p}}{\operatorname{Pr}}\left(t_{y y}^{(2)}-\lambda^{2} t^{(2)}\right)
\end{gathered}
$$

Boundary and interface conditions as defined in Eqs. (50) and (51) can be written in terms of $\psi^{(j)}$ and $t^{(j)}$ as

$$
\begin{aligned}
& \frac{\partial \psi^{(1)}}{\partial y}=\frac{d u_{0}^{(1)}}{d y}, \quad \psi^{(1)}=0 \quad \text { at } \quad y=-1 \\
& \frac{\partial \psi^{(2)}}{\partial y}=0, \psi^{(2)}=0 \quad \text { at } \quad y=1 \\
& \psi_{y}^{(2)}=\frac{\psi_{y}^{(1)}}{m h r}, \quad \psi^{(1)}=\frac{\psi^{(2)}}{m h r}, \quad \psi_{y y}^{(1)}+\lambda^{2} \psi^{(1)}=\frac{\psi_{y y}^{(2)}+\lambda^{2} \psi^{(2)}}{m^{2} h^{2} r} \text {, at } \quad y=0 \\
& -i \lambda u_{0}^{(1)} \psi_{y}^{(1)}+i \lambda \psi^{(1)} u_{0 y}^{(1)}-\lambda^{2} \psi_{y}^{(1)}+\psi_{y y y}^{(1)}-G r t^{(1)}=\frac{1}{r m^{2} h^{3}}\left(\begin{array}{l}
-i \lambda u_{0}^{(2)} \psi_{y}^{(2)}+i \lambda \psi^{(2)} u_{0 y}^{(2)} \\
-\lambda^{2} \psi_{y}^{(2)}+\psi_{y y y}^{(2)}-G r \beta m^{2} r^{2} h^{3} t^{(2)}
\end{array}\right) \text { at } y=0 \\
& t^{(1)}=-\frac{d \theta_{0}^{(1)}}{d y} \quad \text { at } \quad y=-1, t^{(2)}=0 \text { at } \quad y=1 \\
& t^{(1)}=t^{(2)}, \quad t_{y}^{(1)}+i \lambda t^{(1)}=\frac{k}{h}\left(t_{y}^{(2)}+i \lambda t^{(2)}\right) \text { at } \quad y=0
\end{aligned}
$$

We restrict our attention to the real parts of the solutions for the perturbed quantities $\psi, t, u_{1}$ and $v_{1}$.

Consider only small values of $\lambda$ on substituting

$$
\psi(\lambda, y)=\sum_{r=0}^{\infty} \lambda^{r} \psi_{r}, \quad t(\lambda, y)=\sum_{r=0}^{\infty} \lambda^{r} t_{r}
$$

into Eqs. (54) to (59) we obtain to the order of $\lambda$, the following set of ordinary differential equations

Zeroth order

$$
\begin{aligned}
& \frac{d^{2} t_{10}}{d y^{2}}=0 \\
& \frac{d^{4} \psi_{10}}{d y^{4}}-G r \frac{d t_{10}}{d y}=0 \\
& \frac{d^{2} t_{20}}{d y^{2}}=0 \\
& \frac{d^{4} \psi_{20}}{d y^{4}-G r \beta h^{3} m^{2} r^{2} \frac{d t_{20}}{d y}}=0
\end{aligned}
$$


First order

$$
\begin{gathered}
\frac{d^{2} t_{11}}{d y^{2}}=i \operatorname{Pr}\left(u_{0}^{(1)} t_{10}+\frac{d \theta_{0}^{(1)}}{d y} \psi_{10}\right) \\
\frac{d^{4} \psi_{11}}{d y^{4}}=i\left(u_{0}^{(1)} \frac{d^{2} \psi_{10}}{d y^{2}}-\frac{d^{2} u_{0}^{(1)}}{d y^{2}} \psi_{10}\right)+G r \frac{d t_{11}}{d y} \\
\frac{d^{2} t_{21}}{d y^{2}}=i \frac{\operatorname{Pr}}{k m C_{p}}\left(u_{0}^{(2)} t_{20}+\frac{d \theta_{0}^{(2)}}{d y} \psi_{20}\right) \\
\frac{d^{4} \psi_{21}}{d y^{4}}=i\left(u_{0}^{(2)} \frac{d^{2} \psi_{20}}{d y^{2}}-\frac{d^{2} u_{0}^{(2)}}{d y^{2}} \psi_{20}\right)+G r \beta h^{3} m^{2} r^{2} \frac{d t_{11}}{d y}
\end{gathered}
$$

Zeroth order boundary and interface conditions in terms of stream function and temperature are

$$
\begin{gathered}
\frac{d \psi_{10}}{d y}=\frac{d u_{0}^{(1)}}{d y}, \quad \psi_{10}=0 \quad \text { at } \quad y=-1 \\
\frac{d \psi_{20}}{d y}=0, \quad \psi_{20}=0 \quad \text { at } \quad y=1 \\
\frac{d \psi_{10}}{d y}=\frac{1}{m h r} \frac{d \psi_{20}}{d y}, \quad \psi_{10}=\frac{1}{m h r} \psi_{20}, \quad \frac{d^{2} \psi_{10}}{d y^{2}}=\frac{1}{m^{2} h^{2} r} \frac{d^{2} \psi_{20}}{d y^{2}} \text { at } y=0 \\
\frac{d^{3} \psi_{10}}{d y^{3}}-G r t_{10}=\frac{1}{r m^{2} h^{3}}\left(\frac{d^{3} \psi_{20}}{d y^{3}}-G r \beta h^{3} m^{2} r^{2} t_{20}\right) \quad \text { at } \quad y=0 \\
t_{10}=-\frac{d \theta_{0}^{(1)}}{d y} \quad \text { at } y=-1, t_{20}=0 \quad \text { at } \quad y=1 \\
\frac{d t_{10}}{d y}=\frac{k}{h} \frac{d t_{20}}{d y} \text { at } \quad y=0
\end{gathered}
$$

First order boundary and interface conditions in terms of stream function and temperature are

$$
\begin{aligned}
& \frac{d \psi_{11}}{d y}=0, \quad \psi_{11}=0 \quad \text { at } \quad y=-1 \\
& \frac{d \psi_{21}}{d y}=0, \quad \psi_{21}=0 \quad \text { at } \quad y=1 \\
& \frac{d \psi_{11}}{d y}=\frac{1}{m h r} \frac{d \psi_{21}}{d y}, \quad \psi_{11}=\frac{1}{m h r} \psi_{21}, \quad \frac{d^{2} \psi_{11}}{d y^{2}}=\frac{1}{m^{2} h^{2} r} \frac{d^{2} \psi_{21}}{d y^{2}} \text { at } \quad y=0 \\
& -i u_{0}^{(1)} \frac{d \psi_{10}}{d y}+i \frac{d u_{0}^{(1)}}{d y} \psi_{10}+\frac{d^{3} \psi_{11}}{d y^{3}}-G r t_{11}=\frac{1}{r m^{2} h^{3}}\left(-i u_{0}^{(2)} \frac{d \psi_{20}}{d y}+i \frac{d u_{0}^{(2)}}{d y} \psi_{20}+\frac{d^{3} \psi_{21}}{d y^{3}}-G r \beta h^{3} m^{2} r^{2} t_{21}\right) \\
& \text { at } y=0 \\
& t_{11}=0 \quad \text { at } \quad y=-1, t_{21}=0 \quad \text { at } \quad y=1 \\
& t_{11}=t_{21}, \quad \frac{d t_{11}}{d y}+i t_{10}=\frac{k}{h}\left(\frac{d t_{21}}{d y}+i t_{20}\right) \text { at } \quad y=0
\end{aligned}
$$

The set of Eqs. (29) to (32) subjected to boundary and interface conditions Eqs. (41) and (42) have been solved exactly for $u_{0}^{(j)}$ and $\theta_{0}^{(j)}$, and the set of Eqs. (61) and (62) subject to boundary and interface conditions Eqs. (63) and (64) have been solved exactly for $\psi_{j}$ and $t_{j}(j=1,2)$. From these solutions, the first order quantities can be put in the form,

$$
\begin{array}{r}
\psi_{j}=\left(\psi_{r}+i \psi_{i}\right)_{j}=\psi_{j 0}+\lambda \psi_{j 1}, \\
t_{j}=\left(t_{r}+i t_{i}\right)_{j}=t_{j 0}+\lambda t_{j 1} \quad(j=1,2)
\end{array}
$$

where suffix $r$ denotes the real part and $i$ denotes the imaginary part. Considering only the real part, the expression for first order velocity and temperature become

$$
u_{1}^{(j)}=-\cos (\lambda x) \frac{d \psi_{r}^{(j)}}{d y}+\lambda \sin (\lambda x) \frac{d \psi_{i}^{(j)}}{d y},
$$




$$
\begin{gathered}
v_{1}^{(j)}=-\lambda \psi_{r}^{(j)} \sin (\lambda x)-\lambda^{2} \psi_{i}^{(j)} \cos (\lambda x), \\
\theta_{1}^{(j)}=\cos (\lambda x) t_{r}^{(j)}-\lambda \sin (\lambda x) t_{i}^{(j)}
\end{gathered}
$$

The zeroth order, first order and total solutions are given in the Appendix section.

\subsection{Skin friction and Nusselt number:}

The shearing stress $\tau_{x y}$ at any point in the fluid is given by

$$
\begin{aligned}
\tau_{x y} & =\left(\frac{h^{2}}{\rho v^{2}}\right) \bar{\tau}_{x y}=\frac{\partial u}{\partial y}+\frac{\partial v}{\partial x} \\
& =u_{0}^{\prime}(y)+\varepsilon e^{i \lambda x} u_{1}^{\prime}(y)+i \lambda \varepsilon e^{i \lambda x} v_{1}(y),
\end{aligned}
$$

At the wavy wall $y=-1+\varepsilon \cos (\lambda x)$ skin friction take the form

$$
\tau_{w}=\tau_{-1}^{0}+\varepsilon \operatorname{Re}\left(e^{i \lambda x} u_{0}^{\prime \prime}(-1)+u_{1}^{\prime}(-1)\right)
$$

and at the flat wall $y=1$,

$$
\tau_{f}=\tau_{1}^{0}+\varepsilon \operatorname{Re}\left(u_{1}^{\prime}(1)\right)
$$

where

$$
\tau_{-1}^{0}=\left(\frac{d u_{0}^{(1)}}{d y}\right)_{y=-1} \quad \tau_{1}^{0}=\left(\frac{d u_{0}^{(2)}}{d y}\right)_{y=1}
$$

The dimensionless Nusselt number is given by

$$
N u=\frac{\partial \theta}{\partial y}=\theta_{0}^{\prime}(y)+\varepsilon \operatorname{Re}\left(e^{i \lambda x} \theta_{1}^{\prime}(y)\right)
$$

At the wavy wall $y=-1+\varepsilon \cos (\lambda x) \quad N u$ takes the form

$$
N u_{w}=N u_{-1}^{0}+\varepsilon \operatorname{Re}\left(e^{i \lambda x} t^{\prime}(-1)\right) \text {, }
$$

and at the flat wall $y=1$,

$$
N u_{f}=N u_{1}^{0}+\varepsilon \operatorname{Re}\left(e^{i \lambda x} t^{\prime}(1)\right)
$$

where

$$
N u_{-1}^{0}=\left(\frac{d \theta_{0}^{(1)}}{d y}\right)_{y=-1} \quad N u_{1}^{0}=\left(\frac{d \theta_{0}^{(2)}}{d y}\right)_{y=1}
$$

and Re represents the real part

Velocity and temperature solutions are numerically evaluated for several sets of values of the parameters such as, free convective parameter $G r$, viscosity ratio $m$, width ratio $h$ and conductivity ratio $k$. Also, the wall skin friction $\tau_{w}, \tau_{f}$ and the wall Nusselt number $N u_{w}, N u_{f}$ are calculated numerically and some of the qualitative interesting features are presented graphically.

\section{Results and discussion}

Analytical solutions for the steady mixed convection of two immiscible viscous fluids in a vertical channel consists of left wall to be wavy and right wall to be flat is analyzed. The non-linear equations are solved by linearization technique wherein the flow is assumed to be in two parts; a mean part and a perturbed part. Exact solutions are obtained for the mean part and the perturbed part is solved using long wave approximation. The solutions of zeroth order velocity $u_{0}$ and the zeroth order temperature $\theta_{0}$ are applicable to the case of a channel both of whose walls are flat. The solutions for mean $\left(u_{0}, \theta_{0}\right)$ and perturbed part $\left(u_{1}, v_{1}, \theta_{1}\right)$ are evaluated numerically and represented graphically for various governing parameters in Figures (2) to (7). The parameters such as thermal conductivity coefficient ratio, specific heat at constant pressure ratio, density ratio, wave number, Prandtl number, amplitude parameter are fixed as $1,1,1,0.05,0.7,0.02$ respectively for $\lambda x=0.785398$. The other parameters such as Grashof number, viscosity ratio, width ratio, thermal conductivity ratio are fixed as $5,1,1,1$ respectively except the varying one for all the graphs.

The behavior of the non-dimensional zeroth and first order velocities with changes in the convective parameter $G r$ is shown in Figure 2 for different values of wall temperature ratio $\bar{\theta}(\bar{\theta}=-1$ means that the average of the temperatures of the two walls is equal to that of the static temperature, $\bar{\theta}=0$ corresponds to the temperature of flat wall is equal to static temperature and $\bar{\theta}=1$ 
means that the wavy and flat wall are maintained at equal temperature and $\bar{\theta}>1$ implies wall temperatures are unequal). The effect of Grashof number on zeroth order velocity $u_{0}$ is to increase the velocity for $\bar{\theta}=0$ and 1 whereas, for $\bar{\theta}=-1$ zeroth order velocity increases as $G r$ increases for the half of the channel width from the left wall and decreases at the right wall from $y=0$ and onwards i.e., flow reversal is observed at the right wall. The magnitude of velocity $u_{0}$ is optimum for $\bar{\theta}=1$ and minimum for $\bar{\theta}=-1$ and the velocity profiles for $\bar{\theta}=0$ lies in between $\bar{\theta}=-1$ and 1 . Figure 2b depicts the behavior of perturbed (first order solution) quantities $u_{1}$ for $\bar{\theta}=0 \pm 1$. We observed that the fluid velocity $u_{1}$ decreases steadily for a fixed value of $y$ up to $y=-0.55$ approximately, while for values of $y \geq-0.55$ the fluid velocity $u_{1}$ increases for increasing values of Grashof number for all values of $\bar{\theta}$. Figure 2c shows the behavior of the total fluid velocity $u\left(=u_{0}+u_{1}\right)$. The effect of Grashof number on the total velocity $u$ is similar to the zeroth order velocity $u_{0}$ for various $\bar{\theta}$. That is, for $\bar{\theta}=0$ and 1 , velocity increases as $G r$ increases. Physically, an increase in the value of the Grashof number means an increase in the buoyancy force which supports the motion. For $\bar{\theta}=-1$, velocity increases at the left wall (wavy wall) and decreases at the right wall. This is due to the fact that, $\bar{\theta}=-1$ imply, the temperature at the left wall is greater than at the right wall. Hence, velocity increases at the left wall and decreases at the right wall. Figure $2 \mathrm{~d}$ describes the behavior of the total fluid velocity $v\left(=v_{1}\right)$ perpendicular to the channel length and it is noticed that the velocity $v$ diminishes sharply as Grashof number increases for $\bar{\theta}=0 \pm 1$.
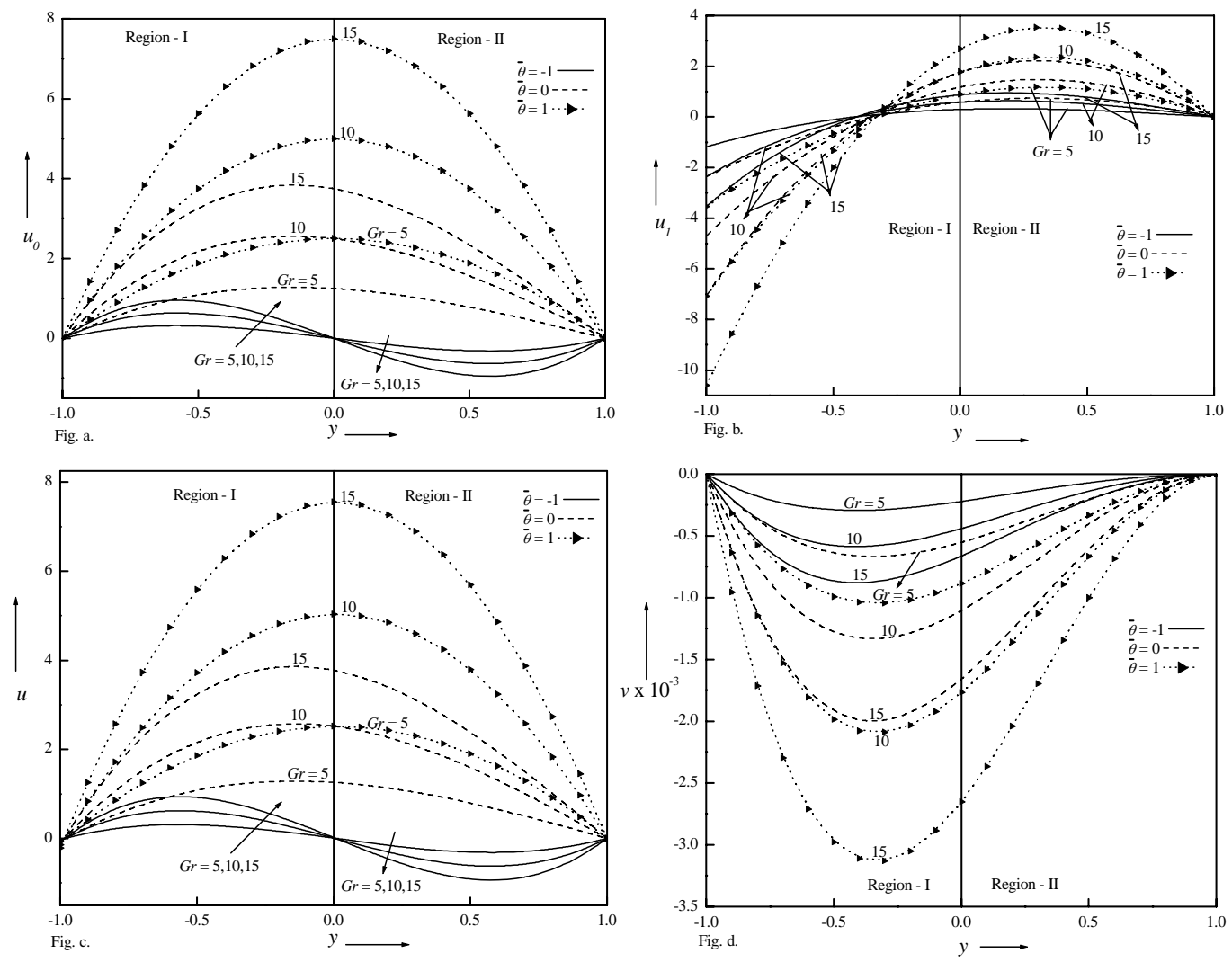

Figure 2: Velocity profile for different values of Grashof number Gr, (a) Zeroth order, (b) First order, (c) Total in $u$ and (d) Total in $v$.

Figure 3 shows the effect of viscosity ratio $m\left(=\mu^{(1)} / \mu^{(2)}\right)$ on the velocity for variations of $\bar{\theta}$. As the viscosity ratio $m\left(=\mu^{(1)} / \mu^{(2)}\right)$ increases, the zeroth order velocity increases in both the regions for wall temperature ratio $\bar{\theta}=0$ and 1 , whereas, for $\bar{\theta}=-1$ zeroth order velocity is invariant in the region-I and decreases in region-II. Flow reversal is observed at the right wall for values of $\bar{\theta}=-1$ only. Figure $3 \mathrm{~b}$ depicts that as the viscosity ratio $m$ increases, first order velocity $u_{1}$ decreases at the left wall i.e., from $y=-1$ to 0 whereas, it increases at the right wall i.e., from $y=0$ to 1 for all values of wall temperature ratio $\bar{\theta}$. The effect of viscosity ratio on total fluid velocity $u\left(=u_{0}+u_{1}\right)$ shows the similar nature as that for zeroth order velocity as seen in 
Figure 3c. Physically, for $\bar{\theta}=0$ and 1, as $m$ increases, the fluid becomes more viscous in region-I and hence velocity is reduced in region-I when compared to region-II. $\bar{\theta}=-1$, temperature in region-I is higher than in region-II. Hence, velocity variations are observed in region-II for variations of viscosity ratio. Physically, higher the temperature lowers the viscosity. Figure $3 \mathrm{~d}$ shows the behavior of the total fluid velocity $v\left(=v_{1}\right)$ perpendicular to the channel length. We notice that as the viscosity ratio increases, velocity $v$ increases in magnitude in both the regions.

The effect of width ratio parameter $h\left(=h^{(2)} / h^{(1)}\right)$ on the velocity is shown in Figure 4. As the parameter $h$ increases, zeroth order velocity increases for wall temperature ratio $\bar{\theta}=0$ and 1 in both the regions. For $\bar{\theta}=-1$ the zeroth order velocity increases as $h$ increases in region-I whereas, it decreases in region-II. It is also observed that flow reversal is observed at the right wall as $h$ increases when $\bar{\theta}=-1$ as seen in Figure 4 a. The effect of width ratio $h$ on first order velocity $u_{1}$ (Figure $4 \mathrm{~b}$ ) shows that as $h$ increases, first order velocity decreases near the left wall (region-I) whereas, it increases at the right wall (region-II) for all values of $\bar{\theta}$. It is observed from Figure 4c that the effect of width ratio $h$ on the total fluid velocity
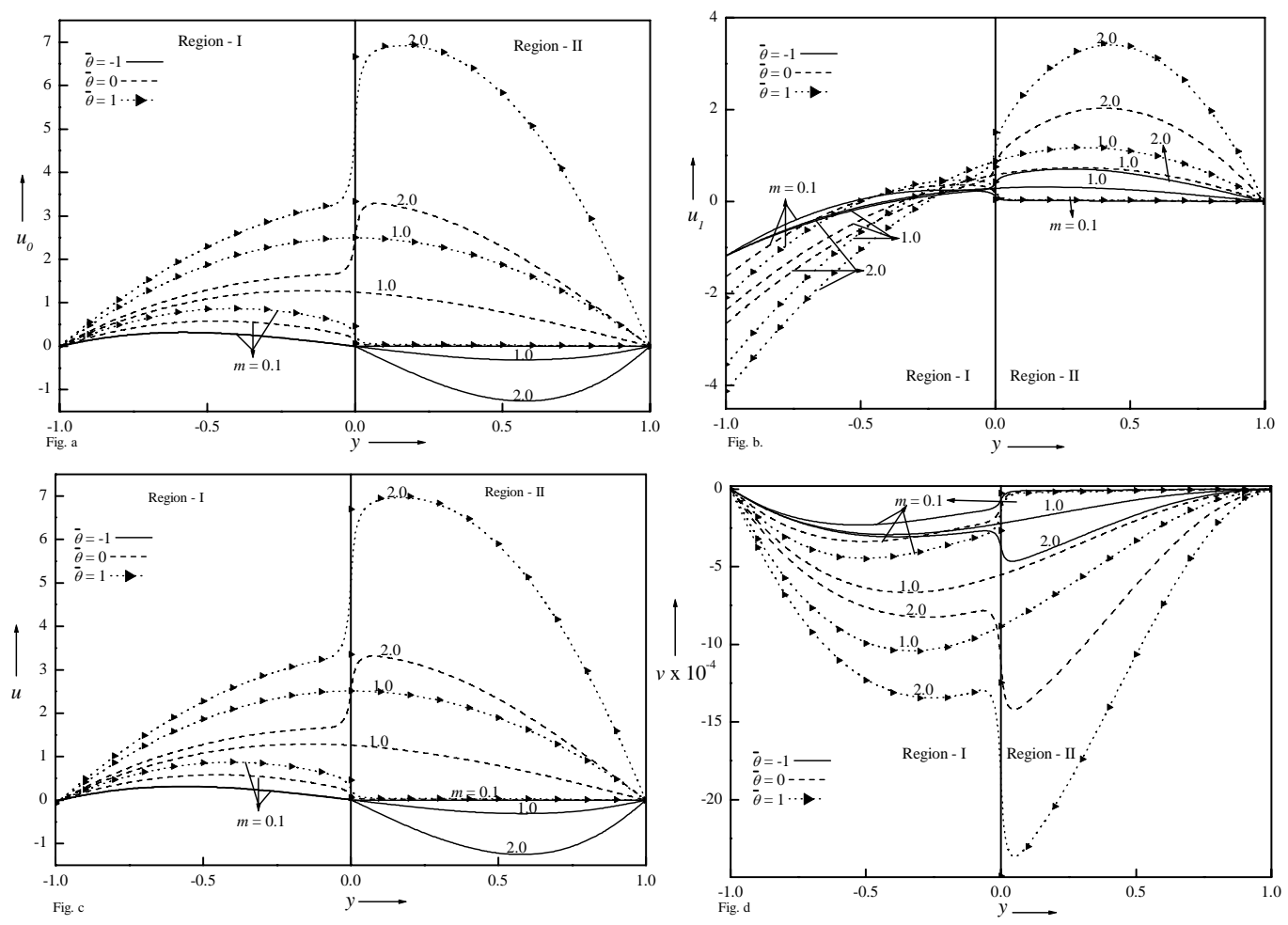

Figure 3: Velocity profile for differet values of viscosity ratio. a. zeroth order, b. first order, c. total velocity in $u$ and d. total velocity in $v$.

$u\left(=u_{0}+u_{1}\right)$ is similar to that on zeroth order velocity $u_{0}$. The effect of width ratio $h$ on total velocity $v\left(=v_{1}\right)$ increases in magnitude as the width ratio $h$ increases, i.e., $v$ diminishes for various values of $h$ as seen in Figure $4 \mathrm{~d}$.

The effect of width ratio $h\left(=h^{(2)} / h^{(1)}\right)$ on zeroth order temperature is to increase the temperature in both regions when $\bar{\theta}=-1$ and 0 whereas, there is no effect of $h$ for $\bar{\theta}=1$ as seen in Figure 5a. Figure 5b shows that the first order temperature decreases in region-I as $h$ increases when $\bar{\theta}=-1$ and 0 . The effect of $h$ is dominant in region-I when compared to region-II. However, for $\bar{\theta}=1$ the first order temperature remains invariant for different values of $h$. The effect of width ratio $h$ on the total temperature is similar to zeroth order temperature as seen in Figure 5c. Physically, as $h$ increases velocity increases; this in tern enhances dissipations and results in enhancement of temperature fields also.

The effect of conductivity ratio $k\left(=k^{(2)} / k^{(1)}\right)$ on the velocity is shown in Figure 6. As the conductivity ratio $k\left(=k^{(2)} / k^{(1)}\right)$ increases, the zeroth order velocity decreases in both the regions for $\bar{\theta}=-1$ and 0 and remains constant for $\bar{\theta}=1$ as seen in Figure 6a. The first order velocity $u_{1}$ increases as the conductivity ratio $k$ increases in region-I for values of $\bar{\theta}=-1$ and 0 from $y=-1$ to -0.55 (approximately) and decreases from $y=-0.55$ to 1 . 

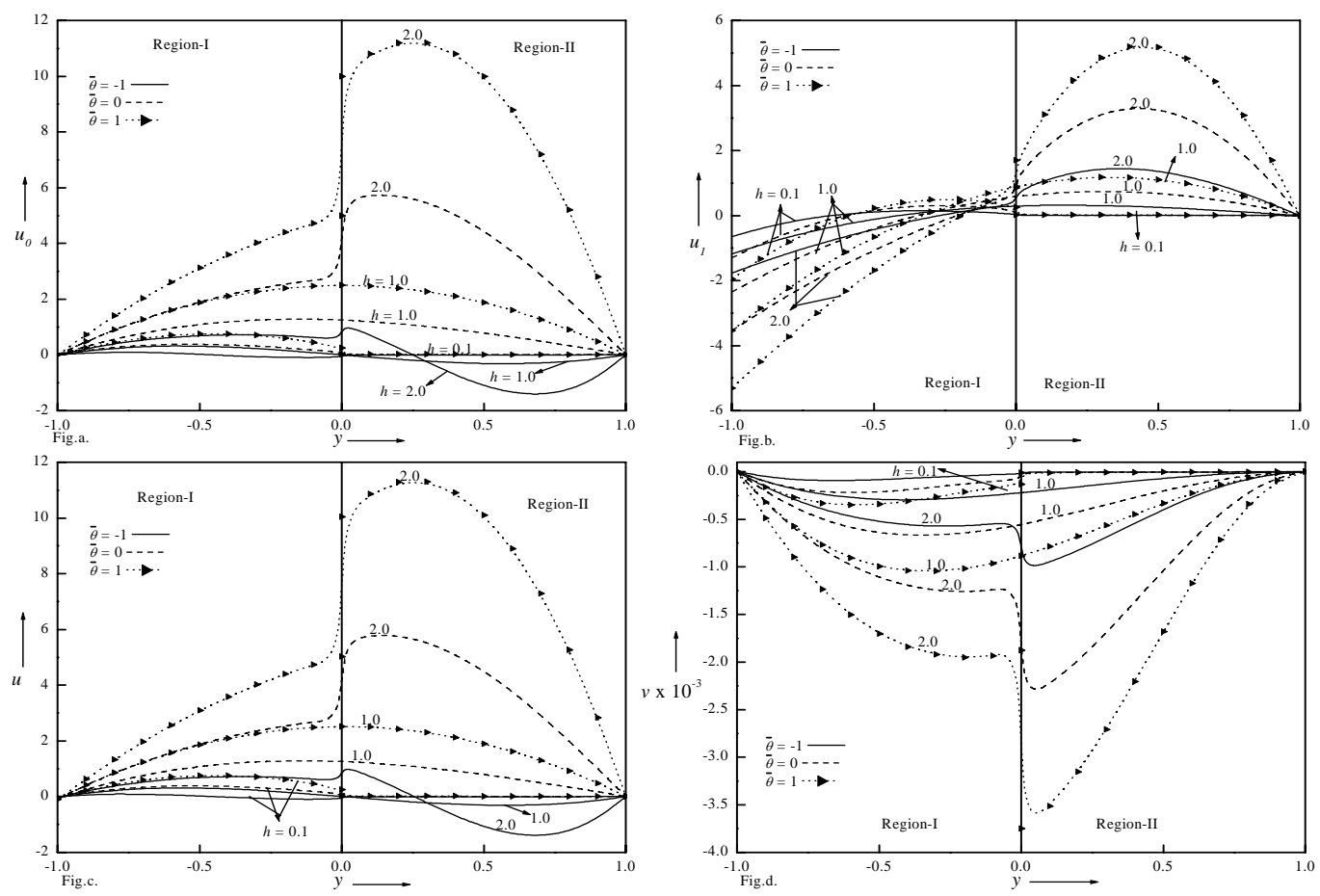

Figure 4: Velocity profile for different values of width ratio $h$. a. zeroth order, b. first order, c. total in $u$ and d. total in $v$.
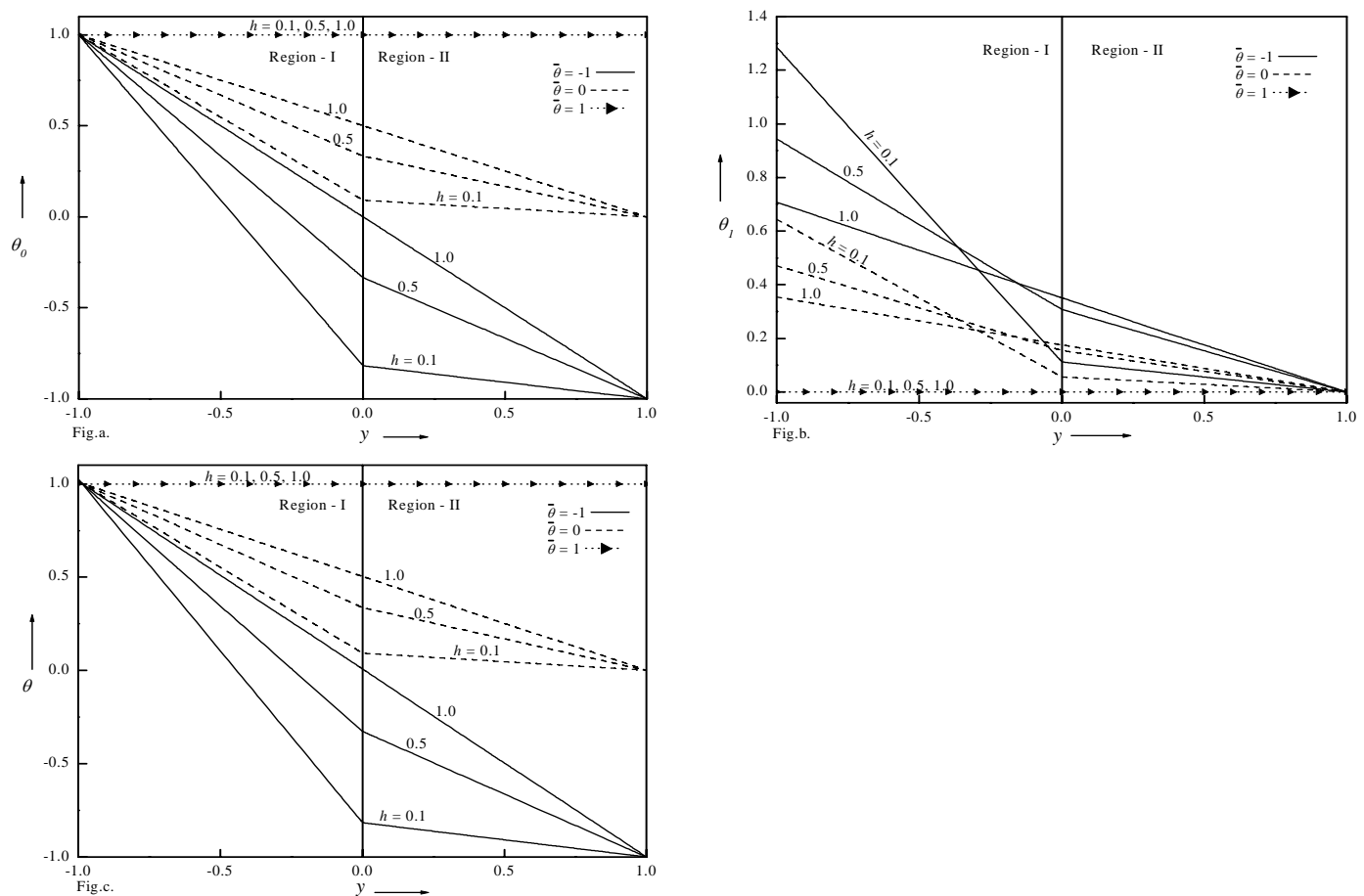

Figure 5: Temperature profile for different values of width ratio. a. zeroth order, b. first order and c. totla temperature profiles. 

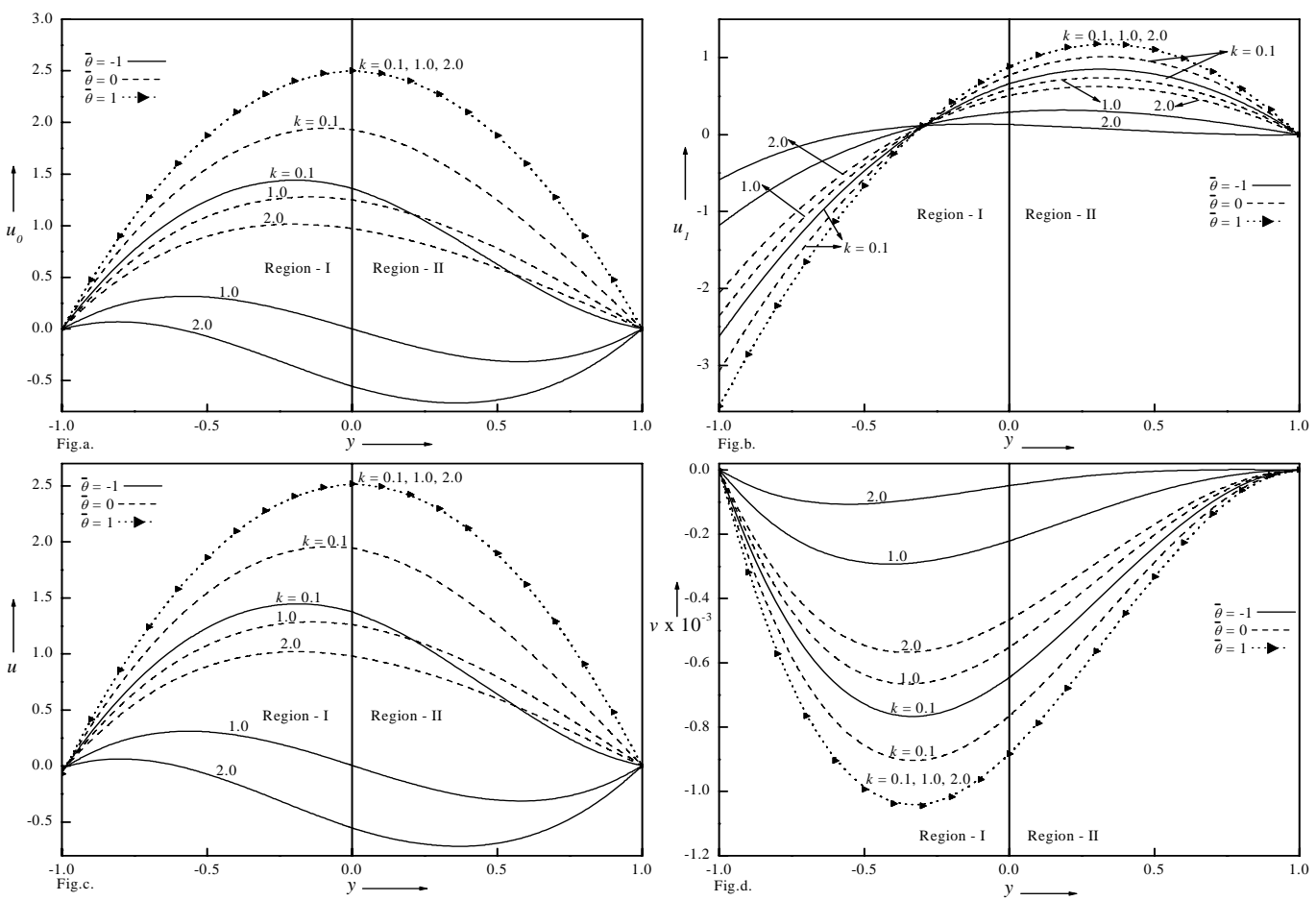

Figure 6: Velocity profile for different values of conductivity ratio $k$. a. zeroth order, b. first order, c. total in $u$ and d. total in $v$.

The first order velocity $u_{1}$ remains constant for different values of $k$ when wall temperature ratio is 1 as shown in Figure 6b. The effect of conductivity ratio $k$ on total velocity $u\left(=u_{0}+u_{1}\right)$ is similar to the zeroth order velocity $u_{0}$ as seen in Figure 6c. Physically, larger the conductivity of the fluid in region-II compared to region-I, the smaller the flow field. The behavior of the total fluid velocity $v\left(=v_{1}\right)$ perpendicular to the channel width decreases in magnitude as conductivity ratio $k$ increases for $\bar{\theta}=-1$ and 0 and remains invariant when $\bar{\theta}=1$ as seen in Figure 6d.

The effect of conductivity ratio $k\left(=k^{(2)} / k^{(1)}\right)$ on zeroth order temperature $\theta_{0}$ is to decrease the temperature in both regions when $\bar{\theta}=-1$ and 0 whereas, there is no effect of $k$ for $\bar{\theta}=1$ as seen in Figure 7a. The first order temperature $\theta_{1}$ increases in both the regions as the conductivity ratio $k$ increases for $\bar{\theta}=-1$ and 0 whereas, it is invariant for $\bar{\theta}=1$ as seen in Figure $7 \mathrm{~b}$. Here also the effect of conductivity ratio $k$ on total temperature $\theta\left(=\theta_{0}+\theta_{1}\right)$ is similar to effect on zeroth order temperature as seen in Figure 7c.

The heat transfer coefficient $N u$ for different values of Grashof number $G r$ and wall temperature ratio $\bar{\theta}$ is shown in Figure 8 . For $\bar{\theta}=0$ the Nusselt number at the wavy wall $N u_{w}$ and Nusselt number at the flat wall $N u_{f}$ remains invariant considering the same fluid in both the regions $(m=h=k=1)$ and variations of viscosity ratio $m$. Varying the width ratio $h$, the Nusselt number at the wavy wall is vary small compared to the Nusselt number at the flat wall, whereas, the Nusselt number at the flat wall is vary small compared to the Nusselt number at the wavy wall for different values of conductivity ratio $k$ as seen in Figure 8a. Similar effect is observed for $\bar{\theta}=-1$ as seen in Figure 8b. The effect of Nusselt number does not vary when $\bar{\theta}=1$ and hence, not shown graphically. It is also observed that the Nusselt number do not change as Grashof number increases.

Figure 9 shows the behavior of skin friction $\tau$ at the channel walls. When $\bar{\theta}=0 \pm 1$, the effect of increase in Grashof number is to increase the skin friction at the wavy wall and decreases at the flat wall. The effect of viscosity ratio $m$ does not affect the skin friction at the wavy wall, whereas, skin friction decreases as viscosity ratio decreases at the flat wall for $\bar{\theta}=-1$. The effect of conductivity ratio $k$ increases the skin friction at the wavy wall, whereas, it decreases at the flat wall for $\bar{\theta}=-1$ as seen in Figure 9a. 

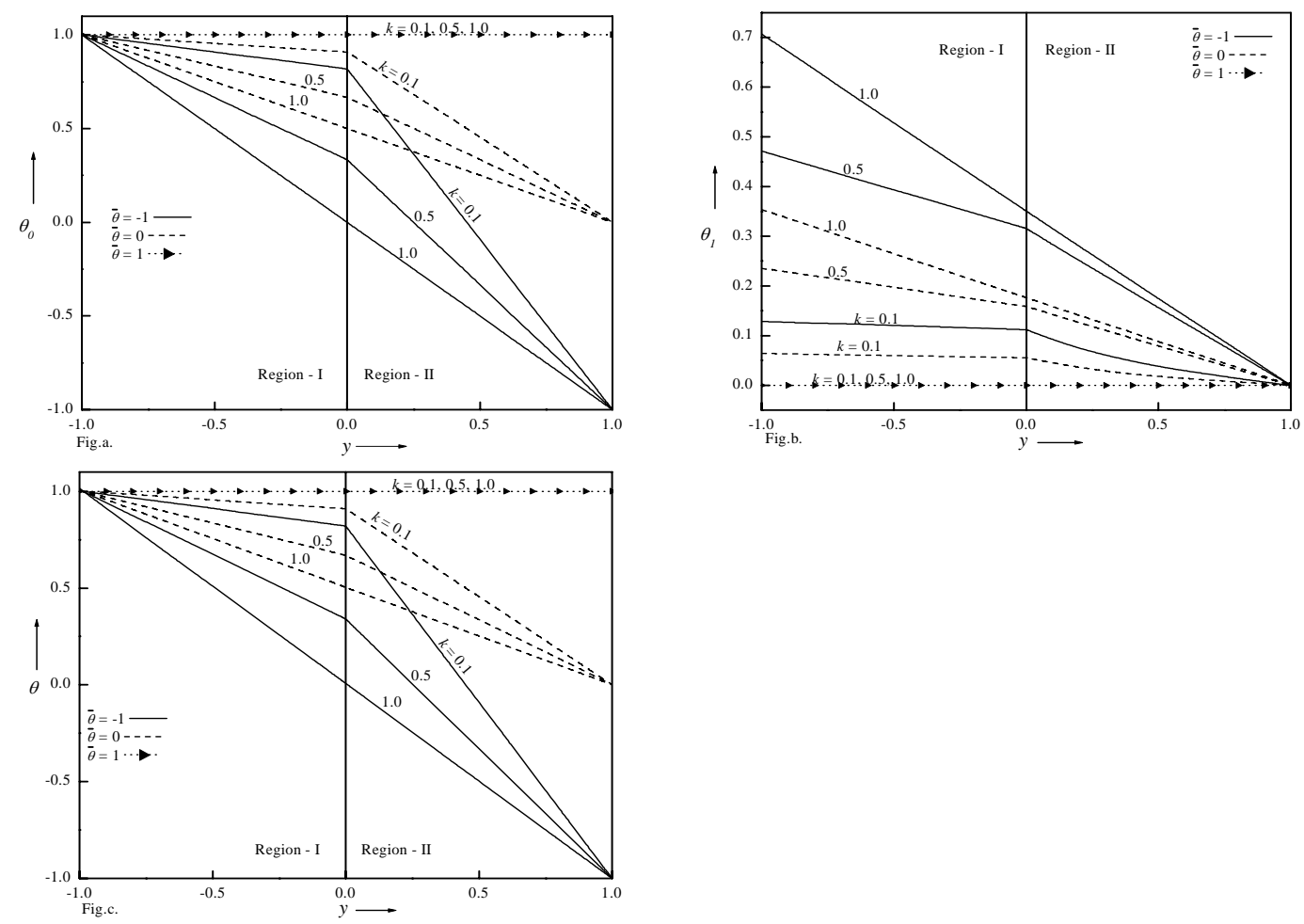

Figure 7: Temperature profile for different values of conductivity ratio $k$. a. zeroth order, b. first order and c. total temperature profiles.
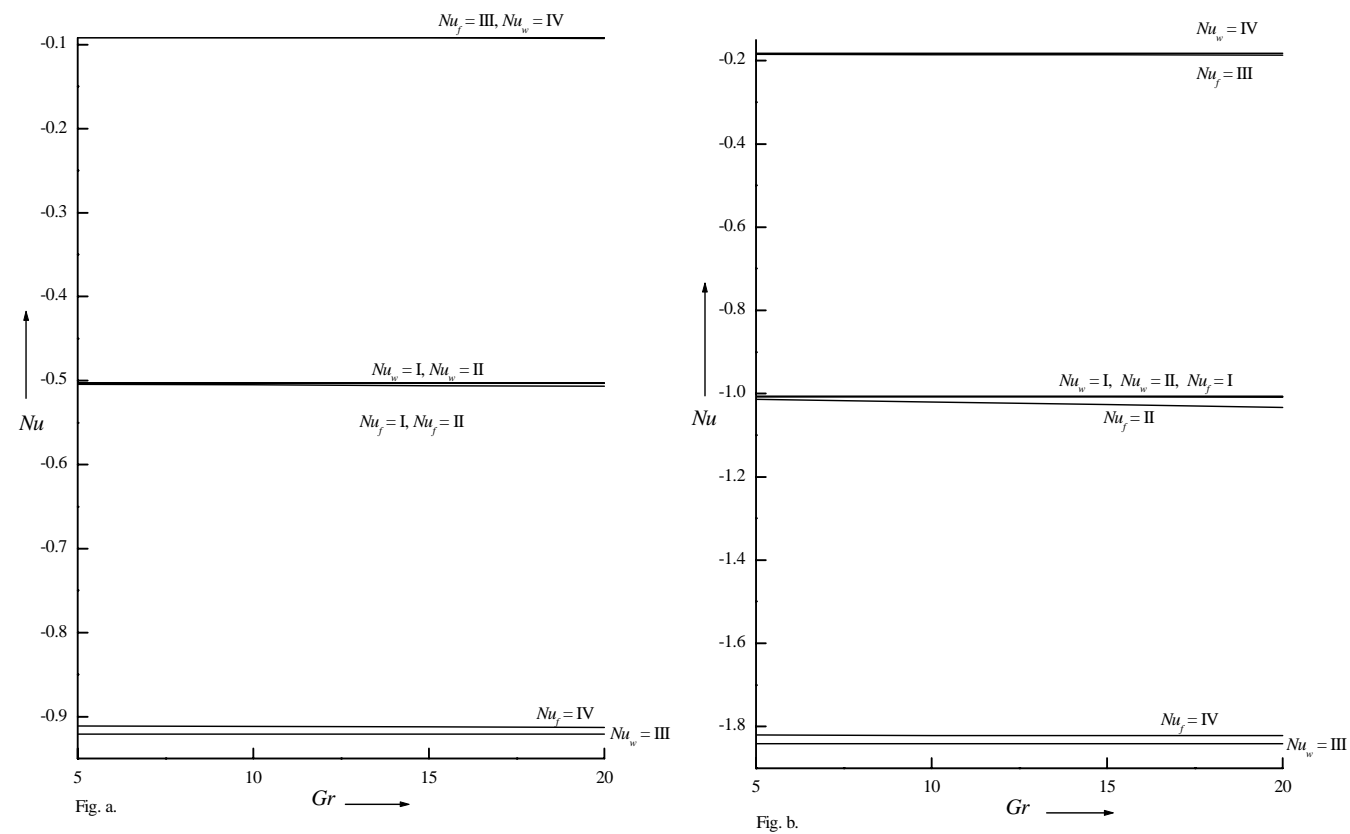

Figure 8: Nusselt number profiles for different values of Grashof number. a. $\bar{\theta}=0$ and b. $\bar{\theta}=-1$

$\begin{array}{lllll} & \text { I } & \text { II } & \text { III } & \text { IV } \\ m & 1 & 0.1 & 1 & 1 \\ h & 1 & 1 & 0.1 & 1 \\ k & 1 & 1 & 1 & 0.1\end{array}$


When the wall temperature ratio $\bar{\theta}$ is zero, as the viscosity ratio decreases, skin friction decreases at the wavy wall and increases at the flat wall. As the width ratio $h$ decreases, skin friction decreases at the wavy wall whereas; it increases at the flat wall. As the conductivity ratio $k$ increases, skin friction decreases at the wavy wall and increases at the flat wall as seen in Figure 9b. For $\bar{\theta}=1$, as the viscosity ratio $m$ increases, skin friction at the wavy wall increases, whereas, it decreases at the flat wall. The effect of width ratio $h$ is similar to the effect of viscosity ratio on the skin friction at both the walls. There is no effect of conductivity ratio $k$ on skin friction at both the walls as seen in Figure 9c.

The effect of convective parameter $G r$ on temperature is shown in Table 1 for various values of wall temperature ratio $\bar{\theta}$. The zeroth order temperature equation consists of only conductivity term; hence, the temperature remains invariant for variations of Grashof number. The temperature at the left wall is 1 , and the right wall is $\bar{\theta}$ and so the temperature for different values of $\bar{\theta}$ varies at the right wall only. The temperature decreases as the wall temperature ratio $\bar{\theta}$ decreases. When the wall temperature ratio is $\bar{\theta}=-1$, there is no effect of Grashof number on the zeroth order temperature. The first order temperature decreases as the Grashof number increases after two decimal points for $\bar{\theta}=-1$. The total temperature decreases as the Grashof number increases as seen in Table $1 \mathrm{a}$ to the order of $10^{-3}$. From Table $1 \mathrm{~b}$ it is seen that for $\bar{\theta}=0$ the similar effect is observed as that of $\bar{\theta}=-1$. For $\bar{\theta}=1$ there is no effect of Grashof number on the temperature as seen in Table 1c. Since the zeroth order energy equation do not have Grashof number, whereas, the first order energy equation consist velocity term which contains Grashof number. Hence, the effect of Grashof number on the temperature is only on the first order and total temperature.

The effect of viscosity ratio $m\left(=\mu^{(1)} / \mu^{(2)}\right)$ on zeroth, first and total temperature is similar to the effect of Grashof number as seen in table 2. The first order temperature decreases as the viscosity ratio increases to two decimal points as seen in Table 2a and 2b. The total temperature effect is same as the first order temperature effect as seen in Table $2 \mathrm{a}$ and $2 \mathrm{~b}$.
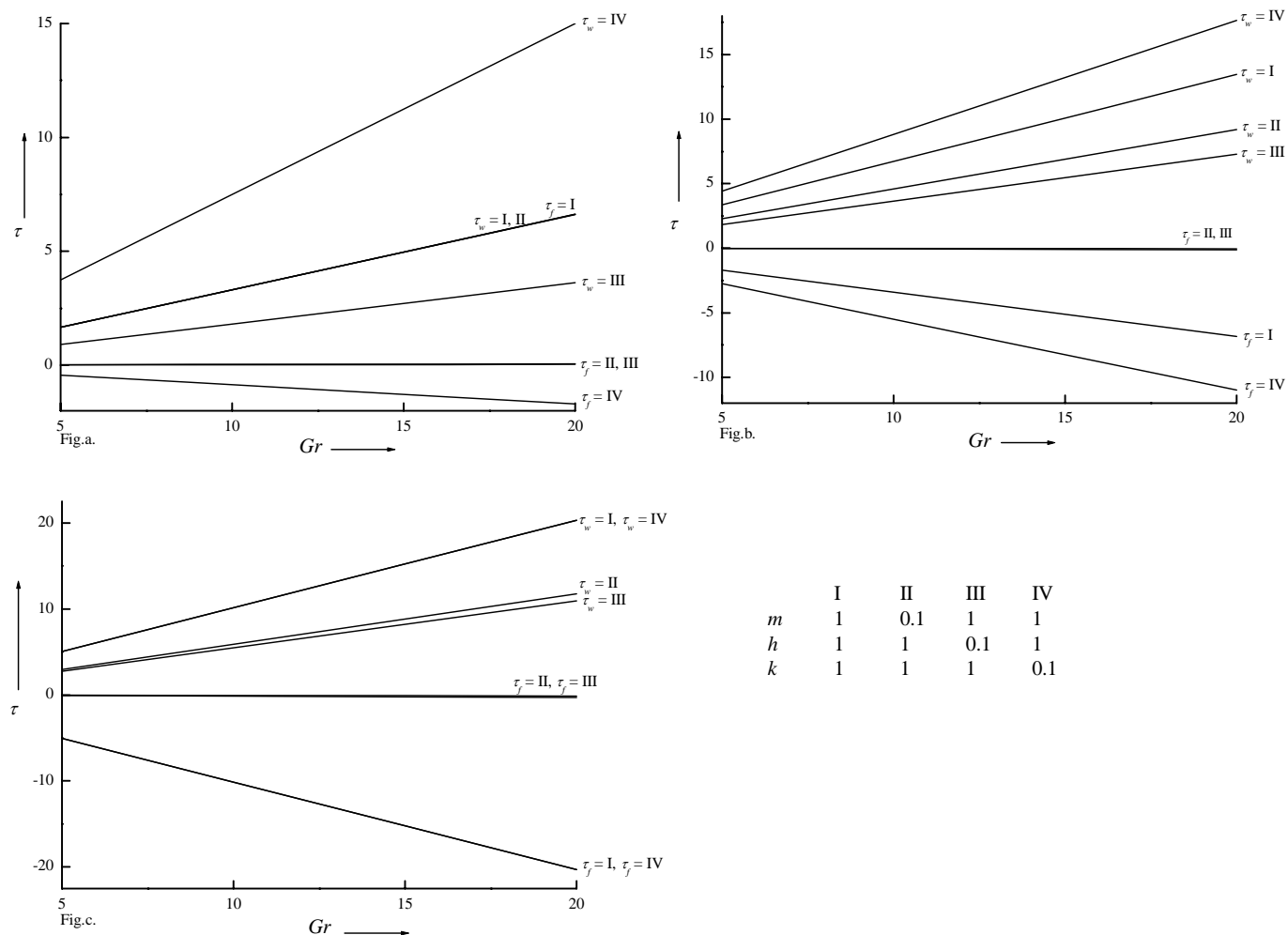

$\begin{array}{lllll} & \text { I } & \text { II } & \text { III } & \text { IV } \\ m & 1 & 0.1 & 1 & 1 \\ h & 1 & 1 & 0.1 & 1 \\ k & 1 & 1 & 1 & 0.1\end{array}$

Figure 9: Skin friction profile for different values of Grashof number. a. $\bar{\theta}=-1$, b. $\bar{\theta}=0$ and c. $\bar{\theta}=1$. 
Table 1. Values of the Temperature field at different Grashof number.

Table 1a. $\bar{\theta}=-1$

\begin{tabular}{|c|c|c|c|c|c|c|c|}
\hline \multirow{2}{*}{$y$} & $\theta_{0}$ & \multicolumn{3}{|c|}{$\theta_{1}$} & \multicolumn{3}{c|}{$\theta=\theta_{0}+\theta_{1}$} \\
\cline { 2 - 8 } & $G r=5,10,15$ & $G r=5$ & $G r=10$ & $G r=15$ & $G r=5$ & $G r=10$ & $G r=15$ \\
\hline-1 & 1 & 0.70711 & 0.70711 & 0.70711 & 1.01414 & 1.01414 & 1.01414 \\
\hline-0.8 & 0.8 & 0.63557 & 0.63474 & 0.63391 & 0.81271 & 0.81269 & 0.81268 \\
\hline-0.6 & 0.6 & 0.56407 & 0.56246 & 0.56084 & 0.61128 & 0.61125 & 0.61122 \\
\hline-0.4 & 0.4 & 0.4927 & 0.49043 & 0.48816 & 0.40985 & 0.40981 & 0.40976 \\
\hline-0.2 & 0.2 & 0.42155 & 0.41883 & 0.41612 & 0.20843 & 0.20838 & 0.20832 \\
\hline 0 & 0 & 0.35068 & 0.3478 & 0.34493 & 0.00701 & 0.00696 & 0.0069 \\
\hline 0 & 0 & 0.35068 & 0.3478 & 0.34493 & 0.00701 & 0.00696 & 0.0069 \\
\hline 0.2 & -0.2 & 0.28011 & 0.27738 & 0.27465 & -0.1944 & -0.19445 & -0.19451 \\
\hline 0.4 & -0.4 & 0.20983 & 0.20752 & 0.20522 & -0.3958 & -0.39585 & -0.3959 \\
\hline 0.6 & -0.6 & 0.13976 & 0.1381 & 0.13644 & -0.5972 & -0.59724 & -0.59727 \\
\hline 0.8 & -0.8 & 0.06984 & 0.06897 & 0.06809 & -0.7986 & -0.79862 & -0.79864 \\
\hline 1 & -1 & $-3.06659 \mathrm{E}-19$ & $-6.13317 \mathrm{E}-19$ & 0 & -1 & -1 & -1 \\
\hline
\end{tabular}

Table 1b. $\bar{\theta}=0$

\begin{tabular}{|c|c|c|c|c|c|c|c|}
\hline \multirow{2}{*}{$y$} & $\theta_{0}$ & \multicolumn{3}{|c|}{$\theta_{1}$} & \multicolumn{3}{c|}{$\theta=\theta_{0}+\theta_{1}$} \\
\cline { 2 - 8 } & $G r=5,10,15$ & $G r=5$ & $G r=10$ & $G r=15$ & $G r=5$ & $G r=10$ & $G r=15$ \\
\hline-1 & 1 & 0.35355 & 0.35355 & 0.35355 & 1.00707 & 1.00707 & 1.00707 \\
\hline-0.8 & 0.9 & 0.31799 & 0.31778 & 0.31758 & 0.90636 & 0.90636 & 0.90635 \\
\hline-0.6 & 0.8 & 0.28244 & 0.28204 & 0.28163 & 0.80565 & 0.80564 & 0.80563 \\
\hline-0.4 & 0.7 & 0.24692 & 0.24635 & 0.24578 & 0.70494 & 0.70493 & 0.70492 \\
\hline-0.2 & 0.6 & 0.21145 & 0.21077 & 0.21009 & 0.60423 & 0.60422 & 0.6042 \\
\hline 0 & 0.5 & 0.17606 & 0.17534 & 0.17462 & 0.50352 & 0.50351 & 0.50349 \\
\hline 0 & 0.5 & 0.17606 & 0.17534 & 0.17462 & 0.50352 & 0.50351 & 0.50349 \\
\hline 0.2 & 0.4 & 0.14074 & 0.14005 & 0.13937 & 0.40281 & 0.4028 & 0.40279 \\
\hline 0.4 & 0.3 & 0.10549 & 0.10491 & 0.10434 & 0.30211 & 0.3021 & 0.30209 \\
\hline 0.6 & 0.2 & 0.0703 & 0.06988 & 0.06946 & 0.20141 & 0.2014 & 0.20139 \\
\hline 0.8 & 0.1 & 0.03514 & 0.03492 & 0.0347 & 0.1007 & 0.1007 & 0.10069 \\
\hline 1 & 0 & 1.53329 & 3.06659 & -6.13317 & 3.06659 & 6.13317 & -1.22663 \\
& & $\mathrm{E}-20$ & $\mathrm{E}-20$ & $\mathrm{E}-20$ & $\mathrm{E}-22$ & $\mathrm{E}-22$ & $\mathrm{E}-21$ \\
\hline
\end{tabular}

Table 1c. $\bar{\theta}=1$

\begin{tabular}{|c|c|c|c|c|c|c|c|}
\hline \multirow{2}{*}{$y$} & $\theta_{0}$ & \multicolumn{3}{|c|}{$\theta_{1}$} & \multicolumn{3}{c|}{$\theta=\theta_{0}+\theta_{1}$} \\
\cline { 2 - 8 } & $G r=5,10,15$ & $G r=5$ & $G r=10$ & $G r=15$ & $G r=5$ & $G r=10$ & $G r=15$ \\
\hline-1 & 1 & 0 & 0 & 0 & 1 & 1 & 1 \\
\hline-0.8 & 1 & 0 & 0 & 0 & 1 & 1 & 1 \\
\hline-0.6 & 1 & 0 & 0 & 0 & 1 & 1 & 1 \\
\hline-0.4 & 1 & 0 & 0 & 0 & 1 & 1 & 1 \\
\hline-0.2 & 1 & 0 & 0 & 0 & 1 & 1 & 1 \\
\hline 0 & 1 & 0 & 0 & 0 & 1 & 1 & 1 \\
\hline 0 & 1 & 0 & 0 & 0 & 1 & 1 & 1 \\
\hline 0.2 & 1 & 0 & 0 & 0 & 1 & 1 & 1 \\
\hline 0.4 & 1 & 0 & 0 & 0 & 1 & 1 & 1 \\
\hline 0.6 & 1 & 0 & 0 & 0 & 1 & 1 & 1 \\
\hline 0.8 & 1 & 0 & 0 & 0 & 1 & 1 & 1 \\
\hline 1 & 1 & 0 & 0 & 0 & 1 & 1 & 1 \\
\hline
\end{tabular}


Table 2. Values of the Temperature field at different viscosity ratio $m(\varepsilon=0.02)$.

Table 2a. $\bar{\theta}=-1$

\begin{tabular}{|c|c|c|c|c|c|c|c|}
\hline \multirow{2}{*}{$y$} & $\theta_{0}$ & \multicolumn{3}{|c|}{$\theta_{1}$} & \multicolumn{3}{c|}{$\theta=\theta_{0}+\theta_{1}$} \\
\cline { 2 - 8 } & $m=0.1,1,2$ & $m=0.1$ & $m=1$ & $m=2$ & $m=0.1$ & $m=1$ & $m=2$ \\
\hline-1 & 1 & 0.70711 & 0.70711 & 0.70711 & 1.01414 & 1.01414 & 1.01414 \\
\hline-0.8 & 0.8 & 0.63599 & 0.63557 & 0.6354 & 0.81272 & 0.81271 & 0.81271 \\
\hline-0.6 & 0.6 & 0.5649 & 0.56407 & 0.56374 & 0.6113 & 0.61128 & 0.61127 \\
\hline-0.4 & 0.4 & 0.49388 & 0.4927 & 0.49221 & 0.40988 & 0.40985 & 0.40984 \\
\hline-0.2 & 0.2 & 0.42297 & 0.42155 & 0.42093 & 0.20846 & 0.20843 & 0.20842 \\
\hline 0 & 0 & 0.35221 & 0.35068 & 0.34996 & 0.00704 & 0.00701 & 0.007 \\
\hline 0 & 0 & 0.35221 & 0.35068 & 0.34996 & 0.00704 & 0.00701 & 0.007 \\
\hline 0.2 & -0.2 & 0.28161 & 0.28011 & 0.27934 & -0.19437 & -0.1944 & -0.19441 \\
\hline 0.4 & -0.4 & 0.21114 & 0.20983 & 0.2091 & -0.39578 & -0.3958 & -0.39582 \\
\hline 0.6 & -0.6 & 0.14074 & 0.13976 & 0.1392 & -0.59719 & -0.5972 & -0.59722 \\
\hline 0.8 & -0.8 & 0.07038 & 0.06984 & 0.06952 & -0.79859 & -0.7986 & -0.79861 \\
\hline 1 & -1 & $-2.83659 \mathrm{E}-19$ & $-3.06659 \mathrm{E}-19$ & $2.45327 \mathrm{E}-19$ & -1 & -1 & -1 \\
\hline
\end{tabular}

Table 2b. $\bar{\theta}=0$

\begin{tabular}{|c|c|c|c|c|c|c|c|}
\hline \multirow{2}{*}{$y$} & $\theta_{0}$ & \multicolumn{3}{|c|}{$\theta_{1}$} & \multicolumn{3}{c|}{$\theta=\theta_{0}+\theta_{1}$} \\
\cline { 2 - 8 } & $m=0.1,1,2$ & $m=0.1$ & $m=1$ & $m=2$ & $m=0.1$ & $m=1$ & $m=2$ \\
\hline-1 & 1 & 0.35355 & 0.35355 & 0.35355 & 1.00707 & 1.00707 & 1.00707 \\
\hline-0.8 & 0.9 & 0.31806 & 0.31799 & 0.31791 & 0.90636 & 0.90636 & 0.90636 \\
\hline-0.6 & 0.8 & 0.28257 & 0.28244 & 0.28227 & 0.80565 & 0.80565 & 0.80565 \\
\hline-0.4 & 0.7 & 0.24709 & 0.24692 & 0.24668 & 0.70494 & 0.70494 & 0.70493 \\
\hline-0.2 & 0.6 & 0.21164 & 0.21145 & 0.21115 & 0.60423 & 0.60423 & 0.60422 \\
\hline 0 & 0.5 & 0.17625 & 0.17606 & 0.17572 & 0.50352 & 0.50352 & 0.50351 \\
\hline 0 & 0.5 & 0.17625 & 0.17606 & 0.17572 & 0.50352 & 0.50352 & 0.50351 \\
\hline 0.2 & 0.4 & 0.14093 & 0.14074 & 0.1404 & 0.40282 & 0.40281 & 0.40281 \\
\hline 0.4 & 0.3 & 0.10566 & 0.10549 & 0.10519 & 0.30211 & 0.30211 & 0.3021 \\
\hline 0.6 & 0.2 & 0.07043 & 0.0703 & 0.07007 & 0.20141 & 0.20141 & 0.2014 \\
\hline 0.8 & 0.1 & 0.03521 & 0.03514 & 0.03502 & 0.1007 & 0.1007 & 0.1007 \\
\hline 1 & 0 & 4.53999 & 1.53329 & 6.13317 & 9.07997 & 3.06659 & 1.22663 \\
& & E-20 & E-20 & E-20 & E-22 & E-22 & E-21 \\
\hline
\end{tabular}

Table 2c. $\bar{\theta}=1$

\begin{tabular}{|c|c|c|c|c|c|c|c|}
\hline \multirow{2}{*}{$y$} & $\theta_{0}$ & \multicolumn{3}{|c|}{$\theta_{1}$} & \multicolumn{3}{c|}{$\theta=\theta_{0}+\theta_{1}$} \\
\cline { 2 - 8 } & $m=0.1,1,2$ & $m=0.1$ & $m=1$ & $m=2$ & $m=0.1$ & $m=1$ & $m=2$ \\
\hline-1 & 1 & 0 & 0 & 0 & 1 & 1 & 1 \\
\hline-0.8 & 1 & 0 & 0 & 0 & 1 & 1 & 1 \\
\hline-0.6 & 1 & 0 & 0 & 0 & 1 & 1 & 1 \\
\hline-0.4 & 1 & 0 & 0 & 0 & 1 & 1 & 1 \\
\hline-0.2 & 1 & 0 & 0 & 0 & 1 & 1 & 1 \\
\hline 0 & 1 & 0 & 0 & 0 & 1 & 1 & 1 \\
\hline 0 & 1 & 0 & 0 & 0 & 1 & 1 & 1 \\
\hline 0.2 & 1 & 0 & 0 & 0 & 1 & 1 & 1 \\
\hline 0.4 & 1 & 0 & 0 & 0 & 1 & 1 & 1 \\
\hline 0.6 & 1 & 0 & 0 & 0 & 1 & 1 & 1 \\
\hline 0.8 & 1 & 0 & 0 & 0 & 1 & 1 & 1 \\
\hline 1 & 1 & 0 & 0 & 0 & 1 & 1 & 1 \\
\hline
\end{tabular}

\section{Conclusion}

When the wall temperatures are 0 and 1 , the Grashof number, viscosity ratio, width ratio promotes the flow whereas, conductivity ratio suppresses the flow. The effect of Grashof number, viscosity ratio, and width ratio on fluid velocity perpendicular to the channel length diminishes the flow whereas, it increases as the conductivity ratio increases. The Nusselt 
number remains invariant on Grashof number and decreases at the wavy wall and increases at the flat as width ratio decreases and conductivity ratio increases. The skin friction increases at the wavy wall and decreases at the flat wall as Grashof number increases for different wall temperature ratio $\bar{\theta}$.

\section{Nomenclature}

a amplitude (m)

$C_{p}^{(j)} \quad$ specific heat at constant pressure $\left(\mathrm{kJ} \mathrm{kg}^{-1} \mathrm{~K}^{-1}\right)$

$C_{p} \quad$ dimensionless specific heat at constant pressure $\left(C_{p}^{(1)} / C_{p}^{(2)}\right)$

$g \quad$ acceleration due to gravity $\left(\mathrm{ms}^{-2}\right)$

Gr Grashof number $\left(h^{(1)^{3}} g \beta \Delta T / v^{(1)^{2}}\right)$

$h \quad$ width ratio of the channel $\left(h^{(2)} / h^{(1)}\right)$

$K \quad$ thermal conductivity $\left(\mathrm{W} \mathrm{m}^{-1} \mathrm{~K}^{-1}\right)$

$k \quad$ thermal conductivity ratio $\left(k^{(2)} / k^{(1)}\right)$

$m \quad$ viscosity ratio $\left(\mu^{(1)} / \mu^{(2)}\right)$

$\mathrm{Nu} \quad$ Nusselt number

$P \quad$ pressure $\left(\mathrm{Nm}^{-2}\right)$

$p \quad$ dimensionless pressure

Pr Prandtl number $\left(C_{p}^{(1)} \mu^{(1)} / K^{(1)}\right)$

$p_{s} \quad$ static pressure $\left(\mathrm{Nm}^{-2}\right)$

$r \quad$ density ratio $\left(\rho^{(2)} / \rho^{(1)}\right)$

Re real part

$T \quad$ temperature $(\mathrm{K})$

$T_{s} \quad$ static temperature $(\mathrm{K})$

$U, V \quad$ velocities along $X$ and $Y$ directions $\left(\mathrm{ms}^{-1}\right)$

$u, v \quad$ dimensionless velocities

$X, Y \quad$ space co-ordinates $(\mathrm{m})$

$x, y \quad$ dimensionless space co-ordinates

\section{Greek Symbols}

$\beta \quad$ dimensionless co-efficient of thermal expansion $\left(\beta^{(2)} / \beta^{(1)}\right)$

$\beta^{(j)} \quad$ co-efficient of thermal expansion

$\varepsilon \quad$ non-dimensional amplitude parameter $\left(a / h^{(1)}\right)$

$\lambda^{*} \quad$ wave length $(\mathrm{m})$

$\lambda \quad$ non-dimensional wave number $\left(\lambda^{*(i)} / h^{(i)}\right)$

$\mu \quad$ viscosity $\left(\mathrm{kg} \mathrm{m}^{-1} \mathrm{~s}^{-1}\right)$

$v \quad$ kinematic viscosity $\left(\mu^{(i)} / \rho^{(i)}\right)$

$\theta \quad$ dimensionless temperature

$\rho \quad$ density $\left(\mathrm{kg} \mathrm{m}^{-3}\right)$

$\rho_{0} \quad$ static density $\left(\mathrm{kg} \mathrm{m}^{-3}\right)$

$\tau \quad$ skin friction

$\psi \quad$ stream function 


\section{Superscripts}

1 and 2 refer quantities for the fluids in region-I and region-II respectively

\section{Appendix}

$$
\begin{aligned}
& \theta_{0}^{(1)}=c_{1} y+c_{2} \\
& u_{0}^{(1)}=l_{1} y^{3}+l_{2} y^{2}+d_{1} y+d_{2} \\
& \theta_{0}^{(2)}=c_{3} y+c_{4} \\
& u_{0}^{(2)}=l_{3} y^{3}+l_{4} y^{2}+d_{3} y+d_{4} \\
& u_{1}^{(1)}=-\cos (\lambda x)\left(4 l_{5} y^{3}+\frac{d_{5}}{2} y^{2}+d_{6} y+d_{7}\right)+\lambda \sin (\lambda x)\left(\begin{array}{l}
9 l_{17} y^{8}+8 l_{18} y^{7}+7 l_{19} y^{6}+6 l_{20} y^{5}+5 l_{21} y^{4} \\
+4 l_{22} y^{3}+\frac{d_{13}}{2} y^{2}+d_{14} y+d_{15}
\end{array}\right) \\
& u_{1}^{(2)}=-\cos (\lambda x)\left(4 l_{6} y^{3}+\frac{d_{9}}{2} y^{2}+d_{10} y+d_{11}\right)+\lambda \sin (\lambda x)\left(\begin{array}{l}
9 l_{23} y^{8}+8 l_{24} y^{7}+7 l_{25} y^{6}+6 l_{26} y^{5}+5 l_{27} y^{4} \\
+4 l_{28} y^{3}+\frac{d_{17}}{2} y^{2}+d_{18} y+d_{19}
\end{array}\right) \\
& v_{1}^{(1)}=-\lambda \sin (\lambda x)\left(l_{5} y^{4}+\frac{d_{5}}{6} y^{3}+\frac{d_{6}}{2} y^{2}+d_{7} y+d_{8}\right)-\lambda^{2} \cos (\lambda x)\left(\begin{array}{l}
l_{17} y^{9}+l_{18} y^{8}+l_{19} y^{7}+l_{20} y^{6}+l_{21} y^{5} \\
+l_{22} y^{4}+\frac{d_{13}}{6} y^{3}+\frac{d_{14}}{2} y^{2}+d_{15} y+d_{16}
\end{array}\right) \\
& v_{1}^{(2)}=-\lambda \sin (\lambda x)\left(l_{6} y^{4}+\frac{d_{9}}{6} y^{3}+\frac{d_{10}}{2} y^{2}+d_{11} y+d_{12}\right)-\lambda^{2} \cos (\lambda x)\left(\begin{array}{l}
l_{23} y^{9}+l_{24} y^{8}+l_{25} y^{7}+l_{26} y^{6}+l_{27} y^{5} \\
+l_{28} y^{4}+\frac{d_{17}}{6} y^{3}+\frac{d_{18}}{2} y^{2}+d_{19} y+d_{20}
\end{array}\right) \\
& \theta_{1}^{(1)}=\cos (\lambda x)\left(c_{5} y+c_{6}\right)-\lambda \sin (\lambda x)\left(l_{7} y^{6}+l_{8} y^{5}+l_{9} y^{4}+l_{10} y^{3}+l_{11} y^{2}+c_{9} y+c_{10}\right) \\
& \theta_{1}^{(2)}=\cos (\lambda x)\left(c_{7} y+c_{8}\right)-\lambda \sin (\lambda x)\left(l_{12} y^{6}+l_{13} y^{5}+l_{14} y^{4}+l_{15} y^{3}+l_{16} y^{2}+c_{11} y+c_{12}\right) \\
& u^{(1)}=l_{1} y^{3}+l_{2} y^{2}+d_{1} y+d_{2}+\varepsilon\left(-\cos (\lambda x)\left(4 l_{5} y^{3}+\frac{d_{5}}{2} y^{2}+d_{6} y+d_{7}\right)+\lambda \sin (\lambda x)\left(\begin{array}{l}
9 l_{17} y^{8}+8 l_{18} y^{7}+7 l_{19} y^{6} \\
+6 l_{20} y^{5}+5 l_{21} y^{4} \\
+4 l_{22} y^{3}+\frac{d_{13}}{2} y^{2} \\
+d_{14} y+d_{15}
\end{array}\right)\right) \\
& u^{(2)}=l_{3} y^{3}+l_{4} y^{2}+d_{3} y+d_{4}+\varepsilon\left(-\cos (\lambda x)\left(4 l_{6} y^{3}+\frac{d_{9}}{2} y^{2}+d_{10} y+d_{11}\right)+\lambda \sin (\lambda x)\left(\begin{array}{l}
9 l_{23} y^{8}+8 l_{24} y^{7} \\
+7 l_{25} y^{6}+6 l_{26} y^{5} \\
+5 l_{27} y^{4}+4 l_{28} y^{3} \\
+\frac{d_{17}}{2} y^{2}+d_{18} y+d_{19}
\end{array}\right)\right) \\
& v^{(1)}=\varepsilon\left(-\lambda \sin (\lambda x)\left(l_{5} y^{4}+\frac{d_{5}}{6} y^{3}+\frac{d_{6}}{2} y^{2}+d_{7} y+d_{8}\right)-\lambda^{2} \cos (\lambda x)\left(\begin{array}{l}
l_{17} y^{9}+l_{18} y^{8}+l_{19} y^{7}+l_{20} y^{6}+l_{21} y^{5} \\
+l_{22} y^{4}+\frac{d_{13}}{6} y^{3}+\frac{d_{14}}{2} y^{2}+d_{15} y+d_{16}
\end{array}\right)\right) \\
& v^{(2)}=\varepsilon\left(-\lambda \sin (\lambda x)\left(l_{6} y^{4}+\frac{d_{9}}{6} y^{3}+\frac{d_{10}}{2} y^{2}+d_{11} y+d_{12}\right)-\lambda^{2} \cos (\lambda x)\left(\begin{array}{l}
l_{23} y^{9}+l_{24} y^{8}+l_{25} y^{7}+l_{26} y^{6}+l_{27} y^{5} \\
+l_{28} y^{4}+\frac{d_{17}}{6} y^{3}+\frac{d_{18}}{2} y^{2}+d_{19} y+d_{20}
\end{array}\right)\right) \\
& \theta^{(1)}=c_{1} y+c_{2}+\varepsilon\left(\cos (\lambda x)\left(c_{5} y+c_{6}\right)-\lambda \sin (\lambda x)\left(l_{7} y^{6}+l_{8} y^{5}+l_{9} y^{4}+l_{10} y^{3}+l_{11} y^{2}+c_{9} y+c_{10}\right)\right) \\
& \theta^{(2)}=c_{3} y+c_{4}+\varepsilon\left(\cos (\lambda x)\left(c_{7} y+c_{8}\right)-\lambda \sin (\lambda x)\left(l_{12} y^{6}+l_{13} y^{5}+l_{14} y^{4}+l_{15} y^{3}+l_{16} y^{2}+c_{11} y+c_{12}\right)\right)
\end{aligned}
$$




$$
\begin{aligned}
& c_{3}=\frac{(\bar{\theta}-1) h}{k+h}, \quad c_{1}=\frac{k c_{3}}{h}, \quad c_{4}=\bar{\theta}-c_{3}, \quad c_{2}=c_{4}, A=G r \beta h^{3} m^{2} r^{2}, l_{1}=-\frac{G r c_{1}}{6}, \quad l_{2}=-\frac{G r c_{2}}{2}, \quad l_{3}=-\frac{A c_{3}}{6}, \\
& l_{4}=-\frac{A c_{4}}{2}, \quad d_{1}=\frac{d_{3}}{m^{2} h^{2} r}, \quad d_{2}=\frac{d_{4}}{m h r}, \quad d_{3}=\frac{\left(l_{2}-l_{1}\right) m^{2} h^{2} r-\left(l_{3}+l_{4}\right) m h}{m h+1}, \quad d_{4}=-d_{3}-l_{3}-l_{4}, c_{5}=\frac{k c_{7}}{h}, \\
& c_{6}=c_{8}, \quad c_{7}=\frac{h c_{1}}{k+h}, c_{8}=-c_{7}, l_{5}=\frac{G r c_{5}}{24}, \quad l_{6}=\frac{A c_{7}}{24}, z_{1}=3 l_{1}-2 l_{2}+d_{1}+4 l_{5}+\frac{A c_{8}}{2}-\frac{G r c_{6}}{2}, \quad z_{2}=-l_{5}-\frac{A c_{8}}{6}+\frac{G r c_{6}}{6} \text {, } \\
& z_{3}=\left(z_{2}+2 z_{1}+\frac{l_{6}}{m h r}\right)(1+m h), \quad z_{4}=\left(z_{1}+\frac{4 l_{6}}{m h r}\right)\left(\frac{3+m h}{2}\right), \quad z_{5}=\left(\frac{5}{6}-\frac{1}{6 m h r}\right)(1+m h), \quad z_{6}=\left(\frac{1}{2}-\frac{1}{2 m h r}\right)\left(\frac{3+m h}{2}\right), \\
& d_{9}=\frac{z_{3}-z_{4}}{z_{5}-z_{6}}, \quad d_{10}=\frac{m h^{2} r}{1+m h}\left(d_{9}\left(\frac{1}{2}-\frac{1}{2 m h r}\right)-z_{1}-\frac{4 l_{6}}{m h r}\right), \quad d_{11}=-4 l_{6}-\frac{d_{9}}{2}-d_{10}, \quad d_{12}=-l_{6}-\frac{d_{9}}{6}-\frac{d_{10}}{2}-d_{11}, \quad d_{5}=d_{9}-A c_{8}+G r c_{6} \text {, } \\
& d_{6}=\frac{d_{10}}{m^{2} h^{2} r} ; \quad d_{7}=\frac{d_{11}}{m h r} ; \quad d_{8}=\frac{d_{12}}{m h r}, \quad l_{7}=\frac{\operatorname{Pr}}{30}\left(c_{1} l_{5}+c_{5} l_{1}\right), \quad l_{8}=\frac{\operatorname{Pr}}{20}\left(c_{5} l_{2}+c_{6} l_{1}+\frac{d_{5} c_{1}}{6}\right), \quad l_{9}=\frac{\operatorname{Pr}}{12}\left(c_{5} d_{1}+c_{6} l_{2}+\frac{d_{6} c_{1}}{2}\right), \\
& l_{10}=\frac{\operatorname{Pr}}{6}\left(c_{5} d_{2}+c_{6} d_{1}+d_{7} c_{1}\right), \quad l_{11}=\frac{\operatorname{Pr}}{2}\left(c_{6} d_{2}+c_{1} d_{8}\right), \quad l_{12}=\frac{\operatorname{Pr}}{30 k m C_{p}}\left(c_{7} l_{3}+c_{3} l_{6}\right), \quad l_{13}=\frac{\operatorname{Pr}}{20 k m C_{p}}\left(c_{7} l_{4}+c_{8} l_{3}+\frac{c_{3} d_{9}}{6}\right), \\
& l_{14}=\frac{\operatorname{Pr}}{12 k m C_{p}}\left(c_{7} d_{3}+c_{8} l_{4}+\frac{c_{3} d_{10}}{2}\right), \quad l_{15}=\frac{\operatorname{Pr}}{6 k m C_{p}}\left(c_{8} d_{3}+c_{7} d_{4}+c_{3} d_{11}\right), \quad l_{16}=\frac{\operatorname{Pr}}{2 k m C_{p}}\left(c_{8} d_{4}+c_{3} d_{12}\right), \quad z_{7}=l_{7}-l_{8}+l_{9}-l_{10}+l_{11} \text {, } \\
& z_{8}=l_{12}+l_{13}+l_{14}+l_{15}+l_{16}, \quad c_{9}=\frac{k\left(c_{11}+c_{8}\right)}{h}-c_{6}, \quad c_{10}=c_{12}, \quad c_{11}=\frac{h\left(z_{7}-z_{8}+c_{6}-\frac{k c_{8}}{h}\right)}{k+h} \quad c_{12}=-z_{8}-c_{11}, \quad p_{1}=6 l_{1} l_{5}+6 G r l_{7}, \\
& p_{2}=10 l_{2} l_{5}+5 G r l_{8}, \quad p_{3}=12 l_{5} d_{1}+\frac{2 l_{2} d_{5}}{3}-2 l_{1} d_{6}+4 G r l_{9}, \quad p_{4}=12 l_{5} d_{2}+d_{1} d_{5}-6 l_{1} d_{7}+3 G r l_{10} \text {, } \\
& p_{5}=d_{2} d_{5}+d_{1} d_{6}-6 l_{1} d_{8}-2 l_{2} d_{7}+2 G r l_{11}, \quad p_{6}=d_{2} d_{6}-2 l_{2} d_{8}+G r c_{9}, \quad p_{7}=6 l_{2} l_{6}+6 A l_{12}, \quad p_{8}=10 l_{4} l_{6}+5 A l_{13}, \\
& p_{9}=12 l_{6} d_{3}+\frac{2 l_{4} d_{9}}{3}-2 l_{3} d_{10}+4 A l_{14}, \quad \quad p_{10}=12 l_{6} d_{3}+d_{3} d_{9}-6 l_{3} d_{11}+3 A l_{15}, \quad p_{11}=d_{4} d_{9}+d_{3} d_{10}-6 l_{3} d_{12}-2 l_{4} d_{11}+2 A l_{16}, \\
& p_{12}=d_{4} d_{10}-2 l_{4} d_{12}+A c_{11}, l_{17}=\frac{p_{1}}{3024}, \quad l_{18}=\frac{p_{2}}{1680}, \quad l_{19}=\frac{p_{3}}{840}, l_{20}=\frac{p_{4}}{360}, \quad l_{21}=\frac{p_{5}}{120}, l_{22}=\frac{p_{6}}{24}, \quad l_{23}=\frac{p_{7}}{3024}, \quad l_{24}=\frac{p_{8}}{1680} \text {, } \\
& l_{25}=\frac{p_{9}}{840}, \quad l_{26}=\frac{p_{10}}{360}, \quad l_{27}=\frac{p_{11}}{120}, \quad l_{28}=\frac{p_{12}}{24}, \quad z_{9}=-d_{4} d_{11}+d_{3} d_{12}-A c_{12}+d_{2} d_{7}-d_{1} d_{8}+G r c_{10} \text { ， } \\
& z_{10}=9 l_{17}-8 l_{18}+7 l_{19}-6 l_{20}+5 l_{21}-4 l_{22}, \quad z_{13}=l_{23}+l_{24}+l_{25}+l_{26}+l_{27}+l_{28}, \quad z_{11}=-l_{17}+l_{18}-l_{19}+l_{20}-l_{21}+l_{22} \text {, } \\
& z_{12}=9 l_{23}+8 l_{24}+7 l_{25}+6 l_{26}+5 l_{27}+4 l_{28}, \quad z_{14}=\left(-2 z_{10}-z_{11}+\frac{z_{13}}{m h r}-\frac{5 z_{9}}{6}\right)(1+m h), \quad z_{15}=\left(z_{10}-z_{12}+\frac{z_{9}}{2}\right)\left(\frac{m h+3}{2}\right) \text {, } \\
& \mathrm{z}_{16}=\left(\frac{5}{6}-\frac{1}{6 m h r}\right)(1+m h), \quad \mathrm{z}_{17}=\left(\frac{1}{2}-\frac{1}{2 m h r}\right)\left(\frac{m h+3}{2}\right), d_{13}=d_{17}+z_{9}, d_{14}=\frac{d_{18}}{m^{2} h^{2} r}, \quad d_{15}=\frac{d_{19}}{m h r}, \quad d_{16}=\frac{d_{20}}{m h r}, \\
& d_{19}=-z_{12}-d_{18}-\frac{d_{17}}{2}, \mathrm{~d}_{17}=\frac{z_{14}+z_{15}}{z_{16}-z_{17}}, \mathrm{~d}_{18}=\frac{m^{2} h^{2} r\left(\frac{z_{9}}{2}+z_{10}-z_{12}+d_{17}\left(\frac{1}{2}-\frac{1}{2 m h r}\right)\right)}{1+m h}, d_{20}=-\frac{d_{17}}{6}-\frac{d_{18}}{2}-d_{19}-z_{13} \text {. }
\end{aligned}
$$

\section{Acknowledgments}

One of the authors J.C. Umavathi would like to thank UGC-New Delhi for the financial support under UGC-Major Research Project.

\section{References}

Bar-Cohen, A. and Kraus, A.D., 1990. Advantages in thermal modeling of electronic components and systems, ASME Press Series, New York, Vol. 2, pp. 41-107.

Blancher, S., Creff, R. and Quere, P. L., 1998. Effect of tollmien schlichting wave on convective heat transfer in a wavy channel part I: Linear analysis, Int. J. Heat Fluid Flow, Vol. 19, pp. 39-48.

Burns, J.C. and Parks, T., 1967. Peristaltic motion, J. Fluid Mech., Vol. 29, pp. 731-743. 
Cesini, G., Ricci, R. and Ruggeri, B., 1992. Ottimizzazione di dissipatori di calore alettati per applicazioni elettronuche. Modello numerico e verifica sperimentale, in: Proc. 10th UIT National Congress, pp. 201-212.

Goldstein, J.L. and Sparrow, E.M., 1977. Heat / mass transfer characteristic for flow in a corrugated wall channel, ASME J. Heat Transfer, Vol. 99, pp. 187-195.

Greiner, M., Chen, R.F. and Wirtz, R.A., 1991. Enhanced heat transfer / pressure drop measured from a flat surface in a grooved channel, ASME J. Heat Transfer, Vol. 113, pp. 498-501.

Jang, J.H. and Yan, W.M., 2004. Mixed convection heat and mass transfer along a vertical wavy surface, Int. J. Heat Mass Transfer, Vol. 47, pp. 419-428.

Kays, W.M. and London, A.L., 1984. Compact heat Exchangers, $3^{\text {rd }}$ ed., McGraw-Hill, New York, (Chapter 1).

Loharsabi, J. and Sahai, V., 1998. Magneto hydrodynamic heat transfer in two phase flow between parallel plates, Appl. Sci. Res., Vol. 45, pp. 53-66.

Malashetty, M.S., Umavathi, J.C. and Leela, V., 2001. Magnetoconvective flow and heat transfer between vertical wavy wall and a parallel flat wall, Int. J. of Applied Mechanics and Engineering, Vol. 6, No. 2, pp. 437-456.

Malashetty, M. S., Umavathi, J. C. and Prathap Kumar, J., 1997. Two phase magnetohydrodynamic flow and heat transfer in an inclined channel, Int. J. Multiphase Flow, Vol. 23, pp. 545-560.

Malashetty, M.S., Umavathi, J.C. and Prathap Kumar, J., 2001. Convective flow and heat transfer in a composite porous medium, J. Porous Media, Vol. 4, pp. 15-22.

Malashetty, M.S., Umavathi, J.C. and Prathap Kumar, J., 2006. Magneto convection of two immiscible fluids in a vertical enclosure, Heat Mass Transfer, Vol. 42, pp. 977-993.

Meyer, H.I. and Garder, A.O., 1954. Mechanics of two immiscible fluids in porous media, J. Appl. Physics, Vol. 25, pp. 14001406.

Ostrich, S., 1952. An analysis of laminar free-convection flow and heat transfer about a flat plate parallel to the direction of the generating body force, NACA, TN -2635, Accession number -93R12788, Documentation ID-19930083498.

Prathap Kumar, J., Umavathi, J.C. and Basavaraj M Biradar, 2010a. Mixed convection of magneto hydrodynamic and viscous fluid in a vertical channel, Int. J. Non-Linear Mechanics, (accepted).

Prathap Kumar, J., Umavathi J.C. and Basavaraj M Biradar, 2010b. Mixed convective flow of immiscible fluids in a vertical channel, Heat Transfer Asian Research, (accepted).

Rees, D.A.S. and Pop, I., 1994. A note on free convection along a vertical wavy surface in a porous medium, ASME J. Heat Transfer, Vol. 116, pp. 505-508.

Selvarajan, S., Tulapurkara, E.G. and Ram, V.V., 1998. A numerical study of flow through wavy-walled channels, J. Numer. Meth. Fluids, Vol. 26, pp. 519-531.

Umavathi, J.C., Abdul Mateen, Chamkha, A.J. and Al-Mudhaf, A., 2006. Oscillatory Hartman two-fluid flow and heat transfer in a horizontal channel, Int. J. Appl. Mech. Engg., Vol. 11, pp. 155-178.

Umavathi, J.C., Chamkha, A.J., Abdul Mateen. and Al-Mudhaf, A., 2005. Unsteady two fluid flow and heat transfer in a horizontal channel, Heat Mass Transfer, Vol. 42, pp. 81-90.

Umavathi, J.C., Manjula, M.H., Pop, I and Liu, I. C., 2007. Flow and heat transfer of couple stress and viscous fluid in a vertical channel, Int. J. Appl. Mech. Engg., Vol. 12, pp. 537-555.

Umavathi, J.C., Liu, I.C. and Shaik Meera, D., 2008. Unsteady flow and heat transfer of three immiscible fluids, Int. J. Appl. Mech. Engg., Vol. 13, pp. 1079-1100.

Usha, R. and Uma, B., 2004. Long waves on a viscoelastic film flow down a wavy incline, Int. J. Hea Mass Transfer, Vol. 39, pp. 1589-1602.

Vafai, K. and Kim, S.J., 1995. On the limitations of the Brinkman-Forchheimer-extended Darcy equation, Int. J. Heat and Fluid Flow, Vol. 16, pp. 11-15.

Vajravelu, K. and Sastri, K. S., 1978. Free convective heat transfer in a viscous incompressible fluid confined between a long vertical wavy wall and a parallel flat wall, J. Fluid Mech. Vol. 86, pp. 365-383.

Wang, C.C. and Chen, C.K., 2001. Transient force and free convection along a vertical wavy surface in micropolar fluids, Int. J. Heat Mass Transfer, Vol. 44, pp. 3241-3251.

Wang, C.C. and Chen, C.K., 2002. Forced convection in a wavy-wall channel, Int. J. Heat Mass Transfer, Vol. 45, pp. 25872595.

Wang, G and Vanka, S.P., 1995. Convective heat transfer in a periodic wavy passages, Int. J. Heat Mass Transfer, Vol. 38, pp. 3219-3230.

Wirtz, R.A., Huang, F and Greiner, M. 1999. Correlation of fully developed heat transfer and pressure drop in a symmetrically grooved channel, ASME J. Heat Transfer, Vol. 121, pp. 236-239.

Yao, L.S., 2006. Natural convection along a vertical complex wavy surface, Int. J. HeatMass Transfer, Vol. 49, pp. 281-286. 


\section{Biographical notes}

J. C. Umavathi received Ph. D degree from Gulbarga University Gulbarga India in 1992. She is a Professor in the department of Mathematics, Gulbarga University, Gulbarga, Karnataka, India. Her research interest includes heat and mass transfer of multiple (Newtonian and non-Newtonian) fluids through channels and rectangular ducts, numerical simulation using Finite differences and Runge-Kutta Gill method, magnetohydradynamics, flow through porous media she has published more than 60 papers in referred International journals. She has also presented more than 20 research articles in National and International conferences. She is currently dealing with few projects sponsored by Government of India.

J. Prathap Kumar received M. Phil. degree from Mangalore University Mangalore in 1990 and Ph. D degree from Gulbarga University Gulbarga India in 2003. He is a associate professor in the department of Mathematics Gulbarga University, Gulbarga, Karnataka, India. His research interest includes heat and mass transfer, dispersion, baffles for flow through various geometries of one and two fluids models. He has published more than 20 papers in referred International journals. He has also presented 5 research articles in national conferences.

M. Shekar received post graduation in Mathematics from Bangalore University, Bangalore, Karnataka, India in 2009. He is working for Ph. D. and he is also a Fellow of research project sponsored by Government of India. His research interest includes heat and mass transfer of two fluid flows for Newtonian and nonNewtonian fluids through wavy channels.

Received September 2010

Accepted November 2010

Final acceptance in revised form November 2010 